\title{
Big Locational Unemployment Differences Despite High Labor Mobility*
}

\author{
Damba Lkhagvasuren ${ }^{\dagger}$ \\ Concordia University and CIREQ
}

October 3, 2012

Considerable labor mobility exists across U.S. states, enough that, if migration arbitrages local unemployment, one might expect very low unemployment differences across states. However, cross-state data reveal large unemployment differences. An equilibrium multi-location model with stochastic worker-location match productivity and within-location trading frictions can account for these facts. In the model, some workers move to, or stay in, a location with high unemployment because they are more productive there than elsewhere. According to the model, labor mobility and aggregate unemployment are negatively related. This prediction is in stark contrast to standard sectoral reallocation theory, but consistent with the U.S. data.

Keywords: local labor market, labor mobility, local and aggregate unemployment, procyclicality of labor mobility, island model, search and matching model

JEL Classifications: E24, J61, J64, J68, J11, R12, R13

${ }^{*}$ I am deeply indebted to Mark Bils, my advisor, for his encouragement and support. I thank the editor, Robert King, and two anonymous referees for detailed comments that greatly improved the paper. I also thank Yoonsoo Lee and Robert Shimer for providing data on gross state product and local unemployment by demographic groups, respectively. I received helpful comments from Árpád Ábrahám, Stephane Auray, Olivier Blanchard, Yongsung Chang, Gordon Dahl, Gordon Fisher, Paul Gomme, Nikolay Gospodinov, Gueorgui Kambourov, Nir Jaimovich, John Kennan, Greg LeBlanc, Shamim Mondal, Toshihiko Mukoyama, Peter Rupert, Lu Zhang, and participants at various seminars and conferences.

${ }^{\dagger}$ Department of Economics, Concordia University, 1455 Maisonneuve Blvd. W, Montreal, QC H3G 1M8, Canada. Telephone: +15148482424 extension 5726. E-mail: damba.1khagvasuren@concordia.ca. 


\section{Introduction}

Data for the U.S. reveal large and persistent differences in unemployment rates across states. The magnitude of these cross-state unemployment differences is roughly the same size as the cyclical variation in the national unemployment rate. At the same time, there is a great deal of labor mobility within the U.S. For example, labor mobility across states is much larger than the total number of unemployed workers who account for the persistent unemployment differences (see Section 2). Given the large and persistent differences in state unemployment rates, and given the high degree of inter-state labor mobility, it seems natural to ask why unemployment rates are so different across states.

One can explain these data features by simply assuming that non-economic factors, such as preference shocks or shifts in local attractiveness, are the driving force of individuals' relocation decisions. However, empirical studies that use both micro- and sub-national-level data consistently find that inter-state migration decisions are influenced to a substantial extent by income and employment prospects. ${ }^{1}$ In addition, the Current Population Survey (CPS) reveals that an inter-state move is more likely to be made for work-related reasons. More important, if workers move across regions for non-economic reasons one would expect no cyclical pattern in labor mobility. However, this is inconsistent with the procyclicality of labor mobility documented below.

This paper explores whether it is possible to have large, persistent unemployment differences across local markets when labor mobility is driven by income and employment. The question is answered by developing an equilibrium multi-sector model built on the foundations of the island model of Lucas and Prescott (1974). ${ }^{2}$ In their model, workers can move between spatially separated competitive markets, referred to as islands. Moreover, the

\footnotetext{
${ }^{1}$ Greenwood (1997) surveys the earlier literature on internal migration. For recent micro studies that relate earnings and mobility at the individual level, see, for example, Borjas, Bronars, and Trejo (1992), Dahl (2002), and Kennan and Walker (2011). Topel (1986) and Blanchard and Katz (1992) show that labor mobility across states is sensitive to local labor market conditions.

${ }^{2} \mathrm{~A}$ representative sample of recent studies that build on the Lucas-Prescott model might include Alvarez and Veracierto (2000), Kambourov and Manovskii (2009), Coen-Pirani (2010) and Alvarez and Shimer (2011).
} 
marginal productivity of labor is decreasing at the local level and firms on the same island are subject to a common productivity shock, below referred to as a local technology shock. Although these features provide a natural framework for thinking about labor flows across different markets, the Lucas-Prescott model alone cannot be used to address the question of locational unemployment and geographic mobility for the following reasons. First, in their model, a worker is unemployed only when in transition between islands, and thus, a worker's unemployment status is not tied to a particular island. Second, in the Lucas-Prescott model, at a point in time, an island can experience either out-migration or in-migration, not both. In the data, one of the key patterns of labor mobility is that a local labor market experiences simultaneous in- and out-migration and the two flows are much larger than the corresponding net migration in absolute terms. In other words, the basic Lucas-Prescott model is ill-suited to address the labor market flows at the heart of this paper.

This paper makes two departures from the Lucas-Prescott model; the results below show that these departures jointly can account for the key features of local unemployment and mobility. The first modification is that within each island, there are trading frictions between firms and workers as modeled in the Mortensen-Pissarides model. ${ }^{3}$ Consequently, an unemployed worker not moving across islands searches for a job locally and becomes employed with a probability of less than one.

The second departure is that a worker's productivity is subject to a shock specific to the worker-location match. ${ }^{4}$ As a result, workers take into account not only the labor market conditions across the islands but also their location-specific productivity. For example, some workers may choose to leave an island with a favorable local technology shock if their idiosyncratic productivity on the island becomes too low to stay. Moreover, many of these out-migrants may choose to relocate to an island with an adverse technology shock if they are more productive there than elsewhere. Therefore, an island can experience simultaneous

\footnotetext{
${ }^{3}$ See, among others, Mortensen and Pissarides (1994), Pissarides (2000), Hall (2005), Shimer (2005), Mortensen and Nagypál (2007), Hagedorn and Manovskii (2008), and Bils, Chang, and Kim (2011).

${ }^{4}$ This is consistent with Borjas et al. (1992), Dahl (2002), and Kennan and Walker (2011), who find that a substantial fraction of variance in the earnings of workers is due to the worker-location match effect.
} 
in- and out-migration.

It is shown below that location-specific productivity is not only important for accounting for large gross labor flows, but it also plays a crucial role in capturing key features of local labor market dynamics. Specifically, when there is insufficient dispersion in location-specific productivity, the model fails to capture the negative relationship between local employment and unemployment (e.g., Blanchard and Katz, 1992) while generating an unreasonably high volatility for local employment.

Models that do not explicitly distinguish between mobility and unemployment cannot explain the observed procyclicality of gross mobility. For example, in the Lucas-Prescott model, aggregate unemployment and mobility are positively related. In contrast, the model developed in this paper can generate a negative correlation between these two variables. These results suggest that introducing within-market trading frictions and location-specific productivity into an otherwise standard island model could greatly improve the model's predictions and thus provide a more flexible equilibrium framework within which important welfare issues can be addressed.

There is a large literature on persistent differences between geographic areas in variables such as income and employment. Among these studies, those that allow for labor mobility mainly focus on net mobility. ${ }^{5}$ For example, Topel (1986) and Blanchard and Katz (1992) study local labor market fluctuations by attributing relative shifts in a local labor force to geographic mobility. Therefore, these papers treat net mobility, but only implicitly. Recent work by Coen-Pirani (2010) makes an important contribution to this literature by explicitly allowing for both net and gross mobility in an equilibrium multi-sector model to analyze labor flows across U.S. states. The current paper is related to his work as it also allows for net and gross mobility but extends his work by including the unemployment dimension. From the point of view of studying regional differences in employment and unemployment, the current paper establishes a link between the mostly empirical literature on local labor market

\footnotetext{
${ }^{5}$ Net mobility refers to the difference between in- and out-migration at the local level, while gross mobility is defined as the number of workers moving between the markets relative to the labor force.
} 
dynamics (e.g., Blanchard and Katz, 1992) and the standard equilibrium unemployment theories (e.g., Lucas and Prescott, 1974 and Mortensen and Pissarides, 1994).

The outline of the rest of the paper is as follows. Section 2 measures cross-state unemployment and inter-state labor mobility. Section 3 presents a simplified version of the model and shows how unemployment and mobility are related in the presence of firm-worker trading frictions and idiosyncratic location-specific productivity. Section 4 analyzes the full version of the model. Section 5 examines time series properties of local employment and unemployment in the model and compares the results with prior empirical work. Section 6 evaluates the role of location-specific productivity in local labor market dynamics. Section 7 discusses the model's implication for the cyclicality of labor mobility. Section 8 concludes.

\section{Facts}

This section shows that there are large and persistent cross-state differences in unemployment. It also compares these differences with interstate labor mobility.

\subsection{Cross-state differences in unemployment}

The coefficient of cross-state variation. Cross-state differences in unemployment are measured using the coefficient of variation of unemployment across states. Let $r_{i, t}$ denote the unemployment rate of state $i$ and $\bar{r}_{t}$ the aggregate unemployment rate of the U.S. at time $t$. Then the coefficient of variation can be written as $\mathrm{CV}_{t}=\sqrt{\frac{1}{51} \sum_{i=1}^{51}\left(r_{i, t}^{\mathrm{R}}-1\right)^{2}}$, where $r_{i, t}^{\mathrm{R}}$ denotes the relative unemployment rate of state $i: r_{i, t}^{\mathrm{R}}=r_{i, t} / \bar{r}_{t} \cdot{ }^{6}$ The coefficient of variation is measured using seasonally adjusted monthly state unemployment and labor force series constructed by the Bureau of Labor Statistics (BLS). ${ }^{7}$ Between Jan. 1976 and May 2011, the coefficient of variation of cross-state unemployment ranges from 0.175 to 0.346 with an average of 0.237 .

A comparison with cyclical and cross-country unemployment. To give an idea of how large this variation is, cross-state unemployment differences are compared with cyclical aggregate

\footnotetext{
${ }^{6}$ For brevity, the District of Columbia of the U.S. is referred to as a state in this paper.

${ }^{7}$ The BLS's methodology of constructing these series is described at http://www.bls.gov/lau/home.htm.
} 
unemployment, which is considered to be one of the most volatile aggregate variables. The data show that the coefficient of variation of monthly aggregate unemployment over the same period is 0.245 . Thus, the cross-sectional unemployment variation is as large as the variation of aggregate unemployment over time. Another dimension where unemployment exhibits considerable variation is across countries. The OECD data reveal that between 2003 and 2010, the coefficient of variation of the unemployment rates of European countries measured by CV average 0.404 . When two outliers, Spain, where average unemployment is more than 12 percent, and Switzerland, where it is less than 4 percent, are excluded, the coefficient of variation becomes 0.355 . These numbers suggest that unemployment differences across the U.S. states are approximately 60-70 percent of the unemployment differences across European countries, suggesting that there are large cross-sectional differences even within a country.

Differences at the individual level. It is possible that differences in unemployment between local labor markets are small for most of the labor force while a few states have disproportionately high or low unemployment. If the cross-state unemployment differences measured by $\mathrm{CV}$ are generated largely by smaller states, then those differences would not be of much interest, at least from a macroeconomic perspective. To see if this is the case, the following weighted variation is considered: $\mathrm{CV}_{t}^{\mathrm{w}}=\sqrt{\sum_{i=1}^{51} \frac{L_{i, t}}{L_{\mathrm{US}, t}}\left(r_{i, t}^{\mathrm{R}}-1\right)^{2}}$, where $L_{i, t}$ denotes state $i$ 's labor force at time $t$ while $L_{\mathrm{US}, t}$ is the U.S. labor force at $t$, i.e., $L_{\mathrm{US}, t}=\sum_{i=1}^{51} L_{i, t}{ }^{8}$ During the sample period, $\mathrm{CV}^{\mathrm{w}}$ averages 0.204 , indicating that spatial differences in unemployment are also large at the individual level.

Controlling for state fixed effects. Blanchard and Katz (1992) find that state relative unemployment rates exhibit no trend. They also find a very low correlation for relative state unemployment rates between time periods 10 to 20 years apart. These suggest that state fixed effects are not large and that the permanent differences in local attractiveness are not

\footnotetext{
${ }^{8}$ Since unemployment of smaller states may have measurement errors due to their small sample size, $\mathrm{CV}^{\mathrm{w}}$ also corrects for a potential upward bias in $\mathrm{CV}$.
} 
the main reason for regional unemployment differences. Nevertheless, to quantify differences in unemployment that are solely due to cyclical factors, the following measure is constructed: $\mathrm{CV}_{t}^{\mathrm{wf}}=\sqrt{\sum_{i=1}^{51} \frac{L_{i, t}}{L_{\mathrm{US}, t}}\left(r_{i, t}^{\mathrm{R}}-\bar{r}_{i}^{\mathrm{R}}\right)^{2}}$, where $\bar{r}_{i}^{\mathrm{R}}$ is the mean relative unemployment rate of state $i$ over the sample period. The coefficient of variation $\mathrm{CV}^{\mathrm{wf}}$ averages 0.148 . This means that, with an aggregate unemployment rate of 6 percent, the one-standard-deviation range of cross-sectional unemployment is 5-7 percent. So, cross-state differences in unemployment remain large even after removing state fixed effects. The online data appendix (Appendix A) explores different ways to measure cross-state unemployment. ${ }^{9}$ The conclusion remains quite robust. Unemployment rate differences measured by $\mathrm{CV}, \mathrm{CV}^{\mathrm{w}}$ and $\mathrm{CV}^{\mathrm{wf}}$ are summarized in Table 1.

\subsection{Mobility}

Using state-level data, Blanchard and Katz (1992) show that migration reduces local unemployment differences. Moreover, the CPS reveals that, within age and educational groups, recent in-migrants are more than twice as likely to be unemployed as incumbent workers (see the data appendix). Given this close relationship between mobility and unemployment at both local and individual levels, cross-state unemployment is compared with inter-state labor mobility.

Gross mobility. Table 2 shows that over the period 1981 to 2000,3 percent of the labor force changed their state of residence each year. To compare this observed annual mobility with cross-state unemployment, I calculate the minimum annual mobility needed to arbitrage cross-state differences in unemployment. Clearly, this minimum mobility is also the number of workers who "create" the observed cross-state unemployment differences. Thus, the minimum number of movers needed to eliminate cross-state unemployment differences can be calculated as $\sum_{i}\left(r_{i}-\bar{r}\right) L_{i} I\left(r_{i}>\bar{r}\right)$, where $I$ is the indicator function, which takes the value 1 if its argument is true and 0 otherwise. Between 1976 and 2010, this minimum

\footnotetext{
${ }^{9}$ Supplementary materials containing the appendices can be found at the end of the paper.
} 
number averages 0.5 percent of the labor force. This is small compared to the observed mobility rate of 3 percent. Although this calculation does not take into account how the local markets respond to mobility and how individuals make their moving decisions, it does suggest that labor mobility is much larger than cross-sectional unemployment.

Net mobility. Another important feature of inter-state labor mobility is that in- and outmigration flows at a local level are larger than the corresponding net migration. To see this, let $m_{i, t}^{\text {in }}$ denote the number of workers who in-migrate to state $i$ during year $t$ relative to the state's labor force of year $t$. Similarly, let $m_{i, t}^{\text {out }}$ denote the number of workers who out-migrate from state $i$ during year $t$ relative to the state's labor force of year $t$. Table 2 shows that these in- and out-migration rates have little variation across states, implying that the net migration rate, $m_{i, t}^{\text {in }}-m_{i, t}^{\text {out }}$, is much smaller than both $m_{i, t}^{\text {in }}$ and $m_{i, t}^{\text {out }}$ in absolute terms. This small net mobility relative to gross mobility will be one of the key data features considered in the quantitative analysis below and thus needs to be quantified. For this purpose, let $\sigma_{m, i}$ denote the standard deviation of the net migration rate of state $i$ over time. Then, overall net mobility, denoted by $\sigma_{m}$, can be defined as a weighted average of these standard deviations using the labor share of each state as the weight. Given the interstate labor flows over the period 1981-2009, $\sigma_{m}=0.011$. It can be seen that $\sigma_{m}$ also measures the shifts in local labor forces due to labor mobility. Therefore, the fact that these shifts are much smaller than the gross mobility of 3 percent also indicates small net mobility. ${ }^{10}$

\section{The homogeneous islands model}

The goal of this paper is to develop an equilibrium multi-sector model that is capable of reproducing the empirical facts presented above. At the same time, the paper also aims to account for key features of local labor market dynamics, including those documented by Blanchard and Katz (1992). In the interest of clarity, the model is presented in two steps. First, the current section considers an economy of a continuum of islands with the same

\footnotetext{
${ }^{10}$ See Coen-Pirani (2010) for other features of inter-state worker flows.
} 
labor market conditions and thus the same unemployment. In the economy, large labor mobility across islands is driven by idiosyncratic location-specific productivity. There is no net mobility in this economy; that is, for each island, in-migration equals out-migration. Workers searching for a job locally become employed with a probability of less than one. This economy is referred to as the homogeneous islands model. This simple model is used to show how trading frictions and location-specific productivity affect unemployment and mobility. Second, the next section introduces a stochastic local technology shock. The shock shifts local labor market conditions and thus generates a gap between in- and out-migration at the local level. The economy with the stochastic local technology shock will be referred to as the heterogeneous islands model.

\subsection{Environment}

The economy is composed of a continuum of islands inhabited by a measure one of workers and a continuum of firms. Time is discrete. Workers and firms are infinitely lived. Workers are either employed or unemployed. Being employed means being matched with a firm. Each period an unemployed worker decides whether to stay on her current island to search for a job or to move to another island to look for a better opportunity. When moving between any two islands, an unemployed worker incurs a fixed moving cost $C$. Workers cannot move across islands while employed. Therefore, every mover is unemployed, while not all unemployed workers are movers. ${ }^{11}$ Workers on the same island can differ by their productivity specific to the island and this location-specific productivity evolves stochastically over time. Let $x$ denote a worker's productivity specific to her current location. Per-period output of a firm-worker match is given by the worker's location-specific productivity $x$.

Within-market frictions. All firm-worker matches are dissolved at an exogenous rate $\lambda$. Firms look for workers by creating vacancies. The flow cost of a vacancy at productivity

\footnotetext{
${ }^{11}$ The data appendix shows that the unemployment gap between movers and stayers in the model is comparable to that in the data.
} 
level $x$ is $k_{x} \cdot{ }^{12}$ Vacancies and unemployed workers meet at random according to a matching technology. Specifically, the number of new matches formed at productivity level $x$ on a particular island is $\Lambda(v(x), \tilde{u}(x))$, where $v(x)$ and $\tilde{u}(x)$ are the number of vacancies and unemployed workers searching at the productivity level $x$ on the island. The matching function $\Lambda$ is non-negative, strictly increasing, concave, and homogeneous of degree one. The probability that each of these $\tilde{u}(x)$ workers finds a job is $f(q(x))=\Lambda\left(1, \frac{1}{q(x)}\right)$, where $q(x)=\tilde{u}(x) / v(x)$ is the queue length. Each of the $v(x)$ vacancies is filled with the probability $\alpha(q(x))=f(q(x)) q(x)$.

The flow utility of a worker searching for a job locally (stayer) is $b$, while the flow utility of a mover is $b-C$. The flow utility of an employed worker is her wage $w$. The wages are determined through Nash bargaining between the worker and the firm over the match surplus, which refers to the value of the match relative to the sum of the value of being unemployed to the worker and the value of being separated to the firm. Workers and firms discount their future by the same factor $\beta$.

Idiosyncratic shocks. By construction, location-specific productivity does not change during the life of a job (or a worker-firm match). However, if a worker who is employed at time $t-1$ at productivity level $x$ becomes unemployed at time $t$, she draws her new productivity, $x_{t}$, from the distribution $Q_{u}\left(x^{\prime} \mid x\right)$. The latter is weakly decreasing in $x$, implying persistence in location-specific productivity. If the new shock $x_{t}$ is high enough, the unemployed worker will stay on her current island and search for a job at the new productivity level. However, if it is too low, the worker will move to another island to look for a better opportunity. In that case, the productivity shock for the new island is drawn from the distribution $Q_{m}(x)$.

Timing of the events. Each time period consists of four stages. At the beginning of each period, some of the old matches are dissolved. At the same time, the pool of unemployed workers on a given island is augmented by new workers arriving from the rest of the economy.

\footnotetext{
${ }^{12}$ In the calibrated version of the model, $k_{x}$ increases with $x$. This might reflect the possibility that hiring at a higher productivity level is more costly as firms might have to hire even more productive workers to interview a potential applicant or to train a newly hired worker.
} 
In the second stage, workers observe their productivity shock, $x$. In the third stage, some of the unemployed individuals could decide to leave their current island to search for a better opportunity elsewhere. These workers arrive at another island at the beginning of the next period. The probability of arriving at a specific island is the same across islands. Also in the third stage, production and vacancy creation occur, while the unemployed workers who decided to stay in the local market search for a job. In the last stage, new matches are realized.

\subsection{Value functions and wages}

Workers. Let $S(x)$ denote the expected lifetime utility value of searching for a job on the current island at productivity level $x$. Let $M$ denote the value to the worker of leaving the current island. Then, the value of being unemployed is $H(x)=\max \{S(x), M\}$. If a worker of productivity $x$ is employed at wage $w$, the lifetime utility is given by

$$
W(x)=w+\beta(1-\lambda) W(x)+\beta \lambda \int H\left(x^{\prime}\right) Q_{u}\left(d x^{\prime} \mid x\right) .
$$

Given the probability that an unemployed worker of productivity $x$ finds a job is $f(q(x))$, the value of searching for a job on the current island is given by

$$
S(x)=b+\beta f(q(x)) W(x)+\beta(1-f(q(x))) H(x) .
$$

The value of leaving the current island is given by

$$
M=b-C+\beta \int H(x) d Q_{m}(x) .
$$

Firms. Let $J(x)$ denote the value to a firm of being matched with a worker of productivity $x$. Since $x$ remains constant during the life of a firm-worker match,

$$
J(x)=x-w+\beta(1-\lambda) J(x) .
$$

The value to a firm of creating a vacancy at productivity level $x$ is given by

$$
V(x)=-k_{x}+\beta \alpha(q(x)) J(x) .
$$


Wages. The wage payment is set as a Nash bargaining solution:

$$
\underset{w}{\operatorname{argmax}}\left\{(W(x ; w)-H(x))^{\gamma}(J(x ; w)-V(x))^{1-\gamma}\right\},
$$

where $0 \leq \gamma \leq 1$ is the worker's bargaining power.

\subsection{Solution}

Let $H_{0}$ denote the value of a worker's continuation utility of arriving at a new island, i.e., $H_{0}=\int H(x) d Q_{m}(x)$. Analogous to Lucas and Prescott (1974), the local labor market equilibrium is characterized by treating $H_{0}$ as a parameter. Once the value of searching for a job in the local labor market is obtained, $H_{0}$ is determined using workers' mobility decisions.

The shock process. To increase the tractability of the model, the following specification of the transition function $Q_{u}\left(x^{\prime} \mid x\right)$ is adopted from Andolfatto and Gomme (1996):

$$
Q_{u}\left(x^{\prime} \mid x\right)= \begin{cases}(1-\psi) G\left(x^{\prime}\right) & \text { if } x^{\prime}<x, \\ \psi+(1-\psi) G\left(x^{\prime}\right) & \text { otherwise }\end{cases}
$$

where $0 \leq \psi \leq 1$ and $G$ denotes the uniform distribution function on the interval $[1-\omega, 1+$ $\omega]$. This means that for newly unemployed workers, location-specific productivity remains unchanged with probability $\psi$, and when it changes, the new productivity shock is drawn from $G$. Further, it is assumed that newly arrived workers also draw their productivity shock from $G$, i.e., $Q_{m}(x)=G(x)$ for all $x$. So, the distribution functions $Q_{m}(x)$ and $Q_{u}\left(x^{\prime} \mid x\right)$ are captured by only two parameters: $\psi$ and $\omega$.

Stayers and firms. Free entry implies that $V(x)=0$ for all $x$. Combining this condition with equations (1) to (6), it can be shown that ${ }^{13}$

$$
\frac{\tilde{\lambda}-\beta \lambda \psi}{1-\beta}\left(b+\frac{\gamma}{1-\gamma} \frac{k_{x}}{q(x)}\right)+\frac{\tilde{\lambda} k_{x}}{\beta(1-\gamma) \alpha(q(x))}=x+\beta \lambda(1-\psi) H_{0}
$$

where $\tilde{\lambda}=1-\beta(1-\lambda)$. Since $\tilde{\lambda}-\beta \lambda \psi>0$, the left-hand side of equation (8) is strictly decreasing in $q(x)$. Therefore, this equation pins down the queue length $q(x)$. Then, using

\footnotetext{
${ }^{13}$ The derivation of the key equations in this section is contained in Appendix B.
} 
equation (5) and the free-entry condition, the productivity-specific unique wage is given by

$$
w(x)=x-\frac{\tilde{\lambda} k_{x}}{\beta \alpha(q(x))} .
$$

To summarize, given $H_{0}$, the local labor market equilibrium is characterized by equations (8) and (9).

It is assumed that the queue length is the same across productivity levels. Let this common queue length be $q_{1}$. Then, for each productivity level, the probability of finding a job is $f\left(q_{1}\right)$. This normalization, along with equation (8), implies that $k_{x}$ is linear in $x$. Then, equation (9) implies that the wage is linear in productivity. Consequently, $S(x)$ is also linear in $x$ :

$$
S(x)=\zeta_{0}+\zeta_{1} H_{0}+\zeta_{2} x
$$

where $\zeta_{2}=\left(\tilde{\lambda}-\beta \lambda \psi+\frac{\tilde{\lambda}(1-\beta)}{\beta \gamma f\left(q_{1}\right)}\right)^{-1}, \zeta_{1}=\beta \lambda(1-\psi) \zeta_{2}$, and $\zeta_{0}=\frac{b}{1-\beta}\left(1-\zeta_{2}(\tilde{\lambda}-\beta \lambda \psi)\right)$. It can be shown that $\zeta_{0}>0,0<\zeta_{1}<\beta$ and $\zeta_{2}>0$. So, higher location-specific productivity means higher lifetime utility.

Movers. Clearly, if the moving cost $C$ is too high or the value of moving $M$ is too low, there will be no labor mobility across the islands. Therefore, in order to have labor mobility, one must have that $S(1-\omega)<M$. Under such a circumstance, there exists a productivity level $x_{c}$ such that $S\left(x_{c}\right)=M$ and $1-\omega<x_{c} \leq 1+\omega$ (see Figure 1). Unemployed workers with productivity below $x_{c}$ leave their current island, while those with productivity equal to or above $x_{c}$ search for a job on their current island. Therefore, the probability that a newly unemployed worker moves to another island is $(1-\psi) G\left(x_{c}\right)$. Using equations (3) and (10), it can be shown that

$$
G\left(x_{c}\right) \equiv \frac{x_{c}-(1-\omega)}{2 \omega}=\nu-\sqrt{(\nu-1)\left(\nu+\frac{\zeta_{0}+\zeta_{2}}{\zeta_{2} \omega}\right)+\frac{\nu}{\omega \zeta_{2}}(C-b)},
$$

where $\nu=\frac{1-\zeta_{1}}{\beta-\zeta_{1}}>1$. Finally, using $x_{c}$ given by equation (11), the value of a worker's continuation utility of arriving at a new island is

$$
H_{0}=\frac{\zeta_{0}-b+C+\zeta_{2} x_{c}}{\beta-\zeta_{1}} .
$$




\subsection{Interdependence of mobility and unemployment}

Given $q_{1}$ and $x_{c}$, the economy-wide mobility rate is

$$
\bar{m}=\frac{1}{1+\frac{1}{1-\psi}\left(\frac{1}{\lambda}+\frac{1}{f\left(q_{1}\right)}\right)\left(\frac{1}{G\left(x_{c}\right)}-1\right)}
$$

and the aggregate unemployment rate is

$$
\bar{r}=\bar{m}\left(1+\frac{1}{(1-\psi) f\left(q_{1}\right)}\left(\frac{1}{G\left(x_{c}\right)}-1\right)\right) .
$$

Using these two equations, one can see some of the key differences between the current model and other commonly used sectoral allocation models. For example, in the Lucas-Prescott model, a worker is unemployed only when moving between two islands and therefore local unemployment is not defined. On the contrary, equation (14) shows that the current model allows for an explicit distinction between unemployment and mobility. Moreover, unlike in the Lucas-Prescott model, there can be unemployment even in the absence of labor mobility. In this regard, a particularly interesting case arises when the volatility of the idiosyncratic productivity shock, $\omega$, goes to zero. Specifically, using equations (11), (13) and (14), it can be shown that $\lim _{\omega \rightarrow 0} \bar{m}=0$ and $\lim _{\omega \rightarrow 0} \bar{r}=\frac{\lambda}{\lambda+f\left(q_{1}\right)}$. The last equation is nothing but the unemployment rate of a standard search and matching model (Pissarides, 2000). So, in the limit as $\omega$ goes to zero, the model converges to the textbook search and matching model. Thus, the model developed in this paper can be thought of as a set of search and matching economies among which workers can move for better employment opportunities. It is useful to keep this analogy in mind when discussing the impact of the local technology shock.

\subsection{An adverse local technology shock}

In the above economy, there are no unemployment differences across islands. However, one can use the above results to see the mechanism through which local unemployment can differ from aggregate unemployment in the presence of high labor mobility. For this purpose, consider an unanticipated, permanent shock to one of the islands, say, island $1 .^{14}$ Suppose

\footnotetext{
${ }^{14}$ For expositional purposes, I focus on permanent shocks for the remainder of the section. One can reach the qualitatively same conclusions by considering a productivity shock of shorter duration as long as the shock affects the expected match surplus of a new firm-worker pair.
} 
that, due to the shock, per-period output of a firm-worker match on the island is now $x z$ (as opposed to $x$ in the absence of the shock), where $z$ is a positive number close to 1 . For the remainder of the paper, $z$ is referred to as a local technology shock.

Proposition 1. An adverse local technology shock $(z<1)$ raises the queue length $q(x)$ and therefore lowers the job-finding rate $f(q(x))$ in the local market for all $x$.

Proof. Replacing $x$ in the right-hand side of equation (8) by $x z$ and using the fact that the left-hand side of the equation is strictly decreasing in $q(x)$, it can be seen that $q(x)$ goes up as $z$ declines. Consequently, the probability of finding a job on the island, $f(q(x))$, declines for all $x$.

Impact on in- and out-migration. Since the adverse shock reduces the match surplus at each productivity level, the productivity-specific wages of the island also decline. As both the productivity-specific wage and the job-finding rate go down, the value of searching for a job on this island, $S(x)$, declines for all $x$. However, since there is a continuum of islands, the value of leaving the island, $M$, remains the same (see Figure 2). As a result, the number of people leaving the island will sharply increase upon realization of the shock. New workers will still come to the island from the rest of the economy, but at a lower rate. These fewer new settlers will have, on average, higher location-specific productivity (i.e., higher $x$ ) for island 1 than those who were arriving before the permanent shock. ${ }^{15}$ So, for island 1, out-migration will be higher than in-migration until the island's labor force reaches a lower permanent level.

Higher or lower unemployment? In one-sector search and matching models an adverse shock to overall productivity raises the aggregate unemployment rate. However, this well-known result may not always hold at the local level, meaning that an adverse local technology

\footnotetext{
${ }^{15}$ Productivity differences of workers on the same island are captured by their location-specific shocks. It is straightforward to introduce individual-specific permanent effects and schooling levels into the model. One can also make individuals' productivity grow over time, for instance, by introducing a probabilisticaging process. Under such extensions, the relationship between productivity and mobility is not necessarily monotonic (Lkhagvasuren, 2007, 2012).
} 
shock $(z)$ may reduce the local unemployment rate. To see this, suppose that the volatility of the location-specific productivity is very small. Then, an adverse local technology shock can make the value to a worker of searching for a job on the island less than the value of moving to other islands, i.e., $S(x)<M$ for all $x$ (see Figure 2). Put differently, when there is insufficient heterogeneity in location-specific productivity, an adverse local technology shock may cause all unemployed workers of island 1 to move to other islands.

At the same time, using Proposition 1, the island's employment will go down in response to the adverse shock. This means that when there is insufficient dispersion in location-specific productivity, employment and unemployment will be positively correlated at the local level, a prediction that stands in sharp contrast to the U.S. data. For example, using state-level data, Blanchard and Katz (1992) show that a drop in local employment is reflected in an immediate increase in local unemployment.

However, on the contrary, if the volatility of productivity is large, there can be unemployed workers whose productivity is high enough to choose to stay on the island and thus the island's unemployment can increase. So, large idiosyncratic productivity shocks are not only important for generating simultaneous in- and out-migration, but they are also crucial in accounting for local fluctuations such as the negative correlation of local employment and unemployment.

\subsection{Responsiveness of local unemployment}

While a substantial volatility of location-specific productivity is necessary to account for the direction of shifts in local unemployment, too large a volatility of location-specific productivity reduces the impact of the local shock on the magnitude of the shifts. The reason is as follows. As the volatility of location-specific productivity increases, workers become choosier when searching across local markets and search for jobs with a significant match quality. Thus, an overly high volatility of the idiosyncratic productivity shock widens the gap between overall productivity and the flow utility of unemployed workers. This makes 
local unemployment less responsive to the local technology shock. ${ }^{16}$

Then, the question is whether there exists a productivity dispersion $(\omega)$ that can account for both the direction and magnitude of shifts in local unemployment while allowing for high labor mobility. The question is addressed in the next section by considering a stochastic local technology shock and calibrating the model using U.S. data. Before going to this numerical analysis, I examine how an aggregate shock affects unemployment and mobility in the homogeneous islands model. The results are useful for understanding the relationship between aggregate unemployment and mobility.

\subsection{Aggregate unemployment and mobility}

Consider a permanent aggregate shock that raises per-period output of all matches in the economy by, say, 1 percent. Since this aggregate shock raises the overall return to migration, the probability that a newly unemployed worker leaves his or her island increases. At the same time, the probability of finding a job will also respond to the aggregate shock.

Proposition 2. An increase in overall productivity raises the job-finding rate for all stayers.

Proof. An increase in overall productivity raises the value of searching for a job on each island (see Proposition 1). This raises the flow utility of separation, $H_{0}$. Then, using equation (8), the job-finding probability $f\left(q_{x}\right)$ increases for all $x$.

Due to the increases in both the job-finding rate and the probability that a newly unemployed worker leaves her current island, workers move more frequently between the islands. So, the aggregate shock raises labor mobility. Since moving across markets takes time and movers are unemployed, higher mobility induced by the aggregate shock puts upward pressure on unemployment. On the other hand, a higher job-finding rate for stayers puts downward pressure on unemployment. Therefore, the net impact of the aggregate shock on aggregate unemployment is analytically ambiguous. Nevertheless, this simple thought experiment indicates that if the job-finding rate does not respond to the aggregate shock, mobility and

\footnotetext{
${ }^{16}$ Bils et al. (2011) also find a negative impact of greater match quality shocks on the volatility of aggregate unemployment.
} 
unemployment in the model will be positively correlated as in Lucas and Prescott (1974). In Section 7 , it will be shown numerically that the effect of the job-finding rate can dominate the mobility effect and thus generate a negative correlation between aggregate unemployment and gross mobility, a prediction consistent with the U.S. data.

\section{The heterogeneous islands model}

Here, each island is subject to a stochastic local technology shock. Because of this technology shock, employment on each island will fluctuate over time. Then, assuming that production takes place under constant returns and requires labor and land, flow output of a firm-worker match will depend negatively on local employment. ${ }^{17}$ This negative dependence is captured by the following per-period output of a firm-worker match:

$$
y(x, z, \tilde{E})=x z \tilde{E}^{-\phi},
$$

where $0<\phi<1, z$ is the island's technology shock, $x$ is the location-specific productivity of the worker, and $\tilde{E}$ is the island's employment relative to economy-wide employment. The local technology shocks are uncorrelated across islands and have a common stationary transition function $\operatorname{Pr}\left(z_{t+1}<z^{\prime} \mid z_{t}=z\right)=\Pi\left(z^{\prime} \mid z\right)$ given by the following autoregressive process: $z_{t+1}=1-\rho+\rho z_{t}+\epsilon_{t}$, where $0<\rho<1$ and $\epsilon_{t}$ is a zero-mean normal random variable with variance $\sigma_{\epsilon}^{2}$. The local technology shock is realized at the beginning of each period.

The local market condition. Let $h$ denote an individual's employment status: $h=0$ if employed and $h=1$ if unemployed. Let $\mu(h, x)$ denote the measure of individuals residing on an island at the moment following the realization of idiosyncratic shocks. Since the extent to which an individual is attached to her current market depends on her employment status and location-specific productivity, the responsiveness of the local labor force to the local technology shock $z$ depends on the measure $\mu$. Therefore, a local labor market is

\footnotetext{
${ }^{17}$ When the supply of the non-labor input is fixed in the short run, flow output's negative dependence on employment arises under a quite general setting. See, for example, Rogerson, Visschers, and Wright (2009) and Coen-Pirani (2010) for models with and without trading frictions, respectively.
} 
characterized by its current technology shock $z$ and the measure $\mu$. Moreover, the next period's measure $\mu^{\prime}$ is determined by the current technology shock $z$ and the current measure $\mu$. Let $\Gamma$ denote this evolution, i.e., $\mu^{\prime}=\Gamma(z, \mu)$. Let $\Phi$ denote the stationary distribution of islands over $(z, \mu)$ implied by $\Pi$ and $\Gamma$ :

$$
\Phi(\mathbb{Z}, \mathbb{M})=\int_{\Gamma(z, \mu) \in \mathbb{M}, z^{\prime} \in \mathbb{Z}} \Pi\left(d z^{\prime} \mid z\right) \Phi(z, d \mu)
$$

for all $z$ and all $(\mathbb{Z} \times \mathbb{M}) \subset(\mathcal{Z} \times \mathcal{M})$, where $\mathcal{Z}$ and $\mathcal{M}$ are sets of all possible realizations of $z$ and $\mu$, respectively.

\subsection{Value functions and wages}

Unlike in the homogeneous islands model, the expected lifetime utility values will now depend on the local labor market condition $\mathbf{s}=(z, \mu)$. Thus, workers and firms have to solve their problem subject to the law of motion $\Gamma$ and the stationary economy-wide distribution $\Phi$.

Workers. To a worker of productivity $x$, the value of being employed at wage $w$ is given by

$$
W(x, \mathbf{s})=w+\beta(1-\lambda) \mathbb{E}\left[W\left(x, \mathbf{s}^{\prime}\right) \mid \mathbf{s}\right]+\beta \lambda \mathbb{E}\left[H\left(x^{\prime}, \mathbf{s}^{\prime}\right) \mid x, \mathbf{s}\right],
$$

where $H(x, \mathbf{s})=\max \{S(x, \mathbf{s}), M\}$ and $\mathbb{E}$ denotes the expectation. The lifetime utility value of searching for a job on the current island is given by

$$
S(x, \mathbf{s})=b+\beta f(q(x, \mathbf{s})) \mathbb{E}\left[W\left(x, \mathbf{s}^{\prime}\right) \mid \mathbf{s}\right]+\beta(1-f(q(x, \mathbf{s}))) \mathbb{E}\left[H\left(x, \mathbf{s}^{\prime}\right) \mid \mathbf{s}\right] .
$$

As in the homogeneous islands model, the probability that a worker arrives at a specific island from her initial move is the same across islands. However, as workers are allowed to make repeat moves, the probability that a mover settles down on a better island is higher. ${ }^{18}$ Then, the expected lifetime utility value of leaving the current island is

$$
M=b-C+\beta \mathbb{E} H(x, \mathbf{s}),
$$

\footnotetext{
${ }^{18} \mathrm{An}$ alternative is to assume directed search across markets under which workers do not go through repeat mobility. However, Kambourov and Manovskii (2009) argue that assuming directed versus random search across markets is less important when the model period is short like the one considered in this paper. Appendix C provides further reasons why it is even less consequential when there is location-specific productivity. Random search across markets is maintained solely for computational reasons, since it greatly reduces the number of dynamic programming states.
} 
where the expectation is taken over both $Q_{m}$ and $\Phi$.

Firms. The value of a match to a firm is

$$
J(x, \mathbf{s})=y(x, z, E)-w+\beta(1-\lambda) \mathbb{E}\left[J\left(x, \mathbf{s}^{\prime}\right) \mid \mathbf{s}\right) .
$$

Then, the value of a vacancy is given by

$$
V(x, \mathbf{s})=-k_{x}+\beta \alpha(q(x, \mathbf{s})) \mathbb{E}\left[J\left(x, \mathbf{s}^{\prime}\right) \mid \mathbf{s}\right]
$$

Wages. As before, the wage payment reflects a Nash bargaining solution:

$$
w(x, \mathbf{s})=\arg \max _{w}\left\{(W(x, \mathbf{s} ; w)-S(x, \mathbf{s}))^{\gamma}(J(x, \mathbf{s} ; w)-V(x, \mathbf{s}))^{1-\gamma}\right\} .
$$

\subsection{Measures}

Given the measure $\mu$, local employment and unemployment are given by $E=\int \mu(0, x) d x$ and $U=\int \mu(1, x) d x$, respectively. As in Section $2, L$ and $r$ denote the local labor force and unemployment rate, respectively: $L=E+U$ and $r=U / L$. Let $\Omega$ denote the decision rule governing whether an unemployed worker stays on her current island: $\Omega(x, \mathbf{s})$ takes on the value 1 if $S(x, \mathbf{s}) \geq M$ and 0 otherwise. Then, the number of workers leaving an island is given by $m(\mathbf{s})=\int(1-\Omega(x, \mathbf{s})) \mu(1, x) d x$. Without loss of generality, normalize the average number of workers per island to one. Then, overall mobility and aggregate unemployment are $\bar{m}=\int m(\mathbf{s}) d \Phi(\mathbf{s})$ and $\bar{r}=\int \mu(1, x) d x d \Phi(\mathbf{s})$, respectively. Moreover, local employment relative to economy-wide employment is $\tilde{E}=\int \mu(0, x) d x /\left(\int \mu(0, x) d x d \Phi(\mathbf{s})\right)$.

Finally, the law of motion of the local labor force, $\Gamma$, is given by:

$$
\mu^{\prime}\left(0, X^{0}\right)=\int_{X^{0}}\left((1-\lambda) \mu(0, x)+\pi_{0}(x, \mathbf{s}) \mu(1, x)\right) d x
$$

and

$$
\mu^{\prime}\left(1, X^{0}\right)=\int_{X^{0}}\left(\bar{m} \frac{d Q_{m}\left(x^{\prime}\right)}{d x^{\prime}}+\pi_{1}\left(x^{\prime}, \mathbf{s}\right) \mu\left(1, x^{\prime}\right)+\int_{\mathcal{X}} \lambda \mu(0, x) \frac{d Q_{u}\left(x^{\prime} \mid x\right)}{d x^{\prime}} d x\right) d x^{\prime}
$$

for all $X^{0} \subset \mathcal{X}$ where $\mathcal{X}$ denotes sets of all possible realizations of $x, \pi_{0}(x, \mathbf{s})=f(q(x, \mathbf{s})) \Omega(x, \mathbf{s})$ and $\pi_{1}(x, \mathbf{s})=(1-f(q(x, \mathbf{s}))) \Omega(x, \mathbf{s})$. Appendix $\mathrm{C}$ contains the definition of the equilibrium as well as the numerical solution method. 


\subsection{Calibration}

The length of the time period is a quarter of a month, which will be referred to as a week. The discount factor $\beta$ is set to $1 / 1.05^{1 / 48}$, a value consistent with an annual interest rate of 5 percent. The elasticity of flow output of a firm-worker match with respect to land is set to that in Coen-Pirani (2010): $\phi=0.015$. This value is consistent with an income share of land in manufacturing estimated by Ciccone (2007). The separation rate is set to the one measured by Shimer (2005); normalizing it to a weekly frequency, $\lambda=0.0083$.

The parameters governing search frictions are adopted from Hagedorn and Manovskii (2008). Specifically, the bargaining power of a worker, $\gamma$, is set to 0.052 and the number of new matches formed at productivity level $x$ on an island is given by $\Lambda(v(x), \tilde{u}(x))=$ $\left((v(x))^{-\eta}+(\tilde{u}(x))^{-\eta}\right)^{-\frac{1}{\eta}}$, where $\eta=0.407$. According to Hagedorn and Manovskii (2008), for a marginal worker, the flow utility of unemployment relative to productivity is 0.955 . This value is used for the flow utility of a stayer relative to the lower bound of location-specific productivity, i.e., $b=0.955(1-\omega)$.

Given the rest of the parameters, the moving cost $C$ is set to target gross mobility of 2.8 percent. As in the homogeneous islands model, the vacancy creation cost $k_{x}$ is assumed to be linear in $x$. The intercept of this linear relationship is chosen to achieve the target unemployment rate of 5.7 percent (Shimer, 2005), while its slope is determined by equation (8).

The local technology shock is calibrated by targeting the persistence and volatility of local labor productivity. As in Ciccone and Hall (1996) and Bauer and Lee (2005), local labor productivity is measured using the logarithm of the ratio of private non-farm gross state product to employment minus the same variable for the entire United States. Between 1974 and 2004, for an average state, the standard deviation of the cyclical shifts of this productivity is $\sigma_{y}=0.027$, while its persistence at an annual frequency is $\rho_{y}=0.655$. These values are targeted to choose $\rho$ and $\sigma_{\epsilon}$. In the model, annual labor productivity of an island is constructed as the weighted average of its weekly labor productivity using weekly employment as the weight. 
The persistence of the location-specific shock $x$ is chosen by combining earlier analytical results and prior studies on labor income dynamics. As discussed earlier, the productivity of an employed worker remains constant during a particular job and changes with probability $1-\psi$ upon job separation. Thus, each week, the productivity of an employed worker remains unchanged with probability $1-\lambda(1-\psi)$. Since the wage is linear in productivity, the persistence of the wage is equal to that of productivity. On the empirical side, estimates of the persistence of individual labor income range from 0.75 to 0.95 at an annual frequency, depending on how measurement error and unobserved effects are treated (Chang and Kim, 2007; Guvenen, 2009). Taking into account the logarithmic scale inherent in the persistence parameter, the midpoint of this range is $0.866 .{ }^{19}$ This value is used for the annual persistence, i.e., $(1-\lambda(1-\psi))^{48}=0.866$. Given $\lambda=0.0083$, this dictates that $\psi=0.697$.

The only remaining parameter is $\omega$, which measures the volatility of location-specific productivity. As discussed in Section 3, the parameter governs the responsiveness of labor mobility to the local technology shock. Thus, the parameter is chosen by targeting net mobility $\sigma_{m}=0.011$, an estimate obtained in Section 2. (Section 6 shows that net mobility $\sigma_{m}$ and the productivity dispersion $\omega$ are indeed inversely related.) For the remainder of the paper, the current calibration is referred to as the benchmark model.

\subsection{Main predictions}

Table 3 displays the parameters of the benchmark model. The targeted moments and key predictions of the model are reported in Table 4 . The table indicates that the model performs well along the targeted moments. Most important, it shows that the model is able to account for large observed cross-sectional differences in unemployment while allowing for high labor mobility. Although not directly targeted, the persistence of the local unemployment rate in the model economy is comparable with that measured from state-level data. I will talk more

\footnotetext{
${ }^{19}$ This value is given by $0.95^{g}$ where $g$ is such that $0.95^{g}=0.75^{1 / g}$. Note that when calculating the persistence of individual income shocks in the model, the effect of the local technology shock $z$ is ignored. This is for the purpose of keeping the calibration consistent with empirical estimates of labor income dynamics, which control for local labor market effects (Chang and Kim, 2007; Guvenen, 2009).
} 
about the local labor market evolution shortly.

The average wage in the economy is 0.965 . Therefore, $C=4.911$ means that the moving cost is one-tenth of annual labor income. The vacancy creation cost $k_{x}$ increases linearly in $x$ and ranges between $k_{1-\omega}=0.794$ and $k_{1+\omega}=1.222$. These costs, along with the matching function parameter $\eta=0.407$, imply overall labor market tightness of 0.625 , which is slightly higher than 0.539 , the value obtained by Hall (2005), but very close to 0.634 , an estimate by Hagedorn and Manovskii (2008). The average monthly job-finding rate in the model is 0.463 , which lies in the range of 0.388 to 0.773 , the values estimated by Hall (2005) using the Job Openings and Labor Turnover Survey.

\section{Additional evidence: time series patterns}

Although Table 4 shows that the model performs well along the dimensions of volatility and persistence of the local unemployment rate, it does not provide a detailed description of local labor market dynamics. Blanchard and Katz (1992) were among the first to analyze local labor market evolutions by considering a set of autoregressive processes for state-level data. This section applies the key time series processes proposed by Blanchard and Katz (1992) to the simulated data. It should be made clear that the purpose of this exercise is not to suggest that the assumptions in the current paper are consistent with those in Blanchard and Katz (1992). Instead, the exercise explores whether the time series patterns of state-level data established by these authors can also be obtained from the model economy.

\subsection{Univariate processes}

First, using simulated data, the following two univariate processes are considered:

$$
\Delta e_{t}=c_{0}+\sum_{j=1}^{4} c_{j} \Delta e_{t-j}+\varepsilon_{e, t}
$$

and

$$
r_{t}=c_{0}+c_{1} r_{t-1}+c_{2} r_{t-2}+\varepsilon_{r, t}
$$


where $\Delta e_{t}$ is the $\log$ annual employment growth at year $t$ (i.e., $\left.\Delta e_{t}=\log \left(E_{t} / E_{t-1}\right)\right), r_{t}$ is the local unemployment rate at year $t$ and $\varepsilon_{e, t}$ and $\varepsilon_{r, t}$ are the innovation terms. Table 5 displays the regression coefficients of these two equations along with the associated impulse responses. It shows that, in response to an innovation of 1.0, employment increases to 1.5 after three years and then in the long run reaches a plateau at 1.3. Blanchard and Katz (1992) report that in response to the same innovation, employment in an average state increases to about 1.5 after three years and then in the long run reaches a plateau at about 1.3. (See Table 1 of Blanchard and Katz, 1992.) They also find that depending on the individual states, the long-run response lies between 1.0 and 2.0. So, the model is able to replicate both the hump shape and the magnitude of the employment response found in state-level data. The impulse response of unemployment is also highly consistent with what they found. The effect of a shock to the unemployment rate falls to only 23 percent of the initial shock within four years and is essentially equal to zero within ten years.

As the upper panel of Table 5 shows, the employment growth exhibits a significant persistence at an annual frequency. This might seem at odds with the local technology shock, which follows an AR(1) process. The reason behind this result is as follows. Suppose that the technology shock can take two values: high and low. Consider an island with the low shock and low employment. If the location is hit by the high shock, the job-finding rate will increase as firms will create vacancies at a higher rate. At the same time, more workers come from the rest of the economy. On the other hand, a shift in local employment at $t$ can be written as

$$
\Delta E_{t}=F_{t} U_{t}-\lambda E_{t}
$$

where $\lambda$ is the job separation rate, $F_{t}$ is the average job-finding rate and $U_{t}$ is the number of unemployed workers of the location at $t$. Given this equation, employment will increase gradually until the location is hit by the low technology shock or the employmentto-unemployment flow of the location balances with its unemployment-to-employment flow. Therefore, the persistence of the job-finding rate, along with net mobility, generates sub- 
stantial persistence in the employment growth.

\subsection{A bivariate process}

In addition to the above univariate processes, Blanchard and Katz (1992) also consider multivariate processes. More specifically, for each state they consider a log-linear system of employment, the employment growth rate, and labor market participation. Since the model developed in this paper does not include a labor market participation decision, results may not be comparable. However, these authors report that estimating a bivariate system of employment and the employment growth rate delivers nearly identical impulse responses for employment and unemployment. Keeping this in mind, the following bivariate process is considered: ${ }^{20}$

$$
\left\{\begin{array}{l}
\Delta e_{t}=c_{1,0}+\sum_{j=1}^{2}\left(c_{1,1, j} \Delta e_{t-j}+c_{1,2, j} \tilde{e}_{t-j}\right)+\varepsilon_{1, t} \\
\tilde{e}_{t}=c_{2,0}+\sum_{j=1}^{2}\left(c_{2,1, j} \Delta e_{t-j+1}+c_{2,2, j} \tilde{e}_{t-j}\right)+\varepsilon_{2, t}
\end{array}\right.
$$

where $\Delta e_{t}$ is, as in the univariate case, the local log employment growth, and $\tilde{e}_{t}$ is the local $\log$ employment rate minus the aggregate log employment rate: $\tilde{e}_{t}=\log \left(E_{t} / L_{t}\right)-\log (1-\bar{r})$. Given this system, the joint responses of the two variables are calculated while using the following one-time shock considered by Blanchard and Katz $(1992):\left(\varepsilon_{1, t}, \varepsilon_{2, t}\right)=(-1,0)$. Although the bivariate system considers the log employment growth and the log employment rate, the results are presented using the responses of log employment and the unemployment rate as in Blanchard and Katz (1992). The estimated joint impulse responses are plotted in the upper panel of Figure 3. The figure shows that in the first year, a decrease in employment of 1 percent is associated with an increase in the unemployment rate of 0.47 percentage point. The effect on the unemployment rate steadily decreases over time and disappears after five to six years. Over time, the effect on employment builds up, to reach a peak of -1.57 percent after three years and a plateau of about -1.05 percent. These joint impulse

\footnotetext{
${ }^{20}$ This system is identical to the trivariate system on page 32 of Blanchard and Katz (1992), except it excludes the participation rate.
} 
responses in simulated data are remarkably consistent with those obtained by Blanchard and Katz (1992) from state-level data. (See Figure 7 of their paper.)

As stated earlier, the purpose of this impulse response analysis is to summarize the time series patterns of local employment and unemployment in the model economy. Therefore, the above results should not necessarily suggest that this paper reaches the same conclusions as those in Blanchard and Katz (1992). For example, the local technology shock in the model follows an $\mathrm{AR}(1)$ process, and therefore, local employment should exhibit mean reversion, at least in the long run. However, Figure 3 shows that, in the model, an employment shock seems to affect local employment permanently. The reason for this counterintuitive prediction is that the assumptions of the employment shock are different between Blanchard and Katz (1992) and the current model.

These authors assume that local demand shocks are one-time random-walk shifts ${ }^{21}$ and these shifts in employment have an immediate impact on unemployment, but not vice versa. ${ }^{22}$ Therefore, the permanent drop in employment in Figure 3 is the impact of imposing these highly restrictive assumptions on the simulated data.

\section{Role of location-specific productivity}

In Section 3, it was argued that $(i)$ a sufficient dispersion in location-specific productivity is important for the negative correlation of local employment and unemployment and $(i i)$ the volatility of the local unemployment rate decreases with the productivity dispersion. To illustrate these points numerically and to provide further intuition for the role of locationspecific productivity, the model is solved for different values of the volatility of locationspecific productivity, $\omega$, while adjusting the moving cost to target gross mobility and keeping the other parameters at their benchmark values. The experiment considers the following two

\footnotetext{
${ }^{21}$ In the Comments and Discussion section of Blanchard and Katz (1992), Robert Hall raises doubt about the empirical basis of this implicit assumption.

${ }^{22}$ Although this assumption seems plausible in a frictionless or market-clearing economy, it is highly restrictive when there are trading frictions. For example, as shown in equation (27), a shift in employment is affected by unemployment. Moreover, given that the monthly job-finding rate is quite high (Table 4), it is hard to expect current unemployment to have no impact on current employment, especially at an annual frequency.
} 
values for $\omega$ : $0.05 \omega^{\mathrm{B}}$ and $1.5 \omega^{\mathrm{B}}$, where $\omega^{\mathrm{B}}$ denotes the benchmark value of the parameter. The last two columns of Table 4 summarize the key results of the experiment. ${ }^{23}$ They show that net mobility, $\sigma_{m}$, and locational unemployment differences, $\mathrm{CV}^{\mathrm{wf}}$, are indeed inversely related to the volatility of location-specific productivity, $\omega$.

To further illustrate the impact of the productivity dispersion, I consider the annual growth of local employment and unemployment. As in Section 5 , let $\Delta e_{t}$ be the $\log \operatorname{local}$ employment growth at year $t$. Similarly, let $\Delta u_{t}$ be the log local unemployment growth at year $t: \Delta u_{t}=\log \left(U_{t} / U_{t-1}\right)$ where, as before, $U_{t}$ is the number of local unemployed workers at year $t$. Table 4 shows that the economy with the lower productivity dispersion generates an unreasonably high volatility in the local employment growth: $\operatorname{std}\left(\Delta e_{t}\right)$ of the economy is six times larger than what is in the state-level data. The volatility of the local unemployment growth, $\operatorname{std}\left(\Delta u_{t}\right)$, of the economy is also much higher than the volatility of the state-level unemployment growth. On the contrary, in both the benchmark model and the economy with the higher productivity dispersion, the volatility of the local unemployment and employment growth is comparable to that measured from state-level data. More important, when there is insufficient productivity dispersion, the model fails to account for the negative correlation between local employment and unemployment.

In addition to these moments, one can also consider the above bivariate process for these two economies. The lower panels of Figure 3 summarize the associated impulse responses. The results show that the positive response of unemployment to the negative employment shock is slightly stronger in the economy with the higher dispersion (i.e., when $\omega=1.5 \omega^{\mathrm{B}}$ ). However, in the economy with the lower productivity dispersion (i.e., when $\omega=0.05 \omega^{\mathrm{B}}$ ), a decrease in local employment is reflected in an immediate decrease in the unemployment rate and an even larger drop in local unemployment, in percentage terms. So, when there is insufficient dispersion in location-specific productivity, the model also cannot replicate the key features of the data documented by Blanchard and Katz (1992).

\footnotetext{
${ }^{23}$ The moving costs in the economies with the productivity dispersion $0.05 \omega^{\mathrm{B}}$ and $1.5 \omega^{\mathrm{B}}$ are, respectively, 2.920 and 6.877 .
} 


\section{Implications for the cyclicality of mobility}

In Section 3, it was shown that both the probability that an unemployed worker moves each period and the probability that a stayer finds a job each period increase with aggregate productivity. Depending on which of the two probabilities responds more to aggregate productivity, overall mobility and aggregate unemployment are positively or negatively related. This section introduces a permanent aggregate productivity shock and explores the relationship between aggregate unemployment and mobility. Specifically, the model is simulated while raising both the local technology shock of each island and the idiosyncratic productivity shock of each match by 1 percent. ${ }^{24}$

Table 6 summarizes the responses of the key aggregate variables. It shows that the permanent shock lowers aggregate unemployment while raising overall mobility, the average wage and the total number of vacancies. These responses are quite consistent with both the procyclicality of labor mobility in the U.S. shown in Figure 4, and Abraham and Katz (1986), who argue that shifts in unemployment are primarily driven by aggregate shocks.

It should be stressed that the Lucas-Prescott model predicts counter-cyclical labor mobility. Therefore, the above results suggest that within-market frictions might be essential in understanding how unemployment and mobility are related and that ignoring such frictions could lead to an important oversight regarding how the labor force reallocates across sectors over the business cycle.

\section{Conclusions}

Motivated by large cross-state unemployment rate differences as well as a high degree of inter-state labor mobility, this paper constructs an equilibrium model of labor mobility and

\footnotetext{
${ }^{24}$ Although it is straightforward to introduce a persistent aggregate shock into the model, its solution imposes a heavy computational burden as both the law of motion $\Gamma$ and the distribution $\Phi$ are no longer time-invariant. On the other hand, Mortensen and Nagypál (2007) argue that when the persistence of the aggregate shock is high, the steady-state comparisons provide an adequate approximation for the elasticity of the vacancy-unemployment ratio to aggregate productivity. Since this ratio is key to generating the negative correlation between unemployment and mobility, the impact of the above permanent shock can also be interpreted as an approximate measure of the model's response to a highly persistent aggregate shock.
} 
job search by merging two central frameworks of equilibrium unemployment: the island model (e.g., Lucas and Prescott, 1974) and the search and matching model (e.g., Mortensen and Pissarides, 1994). The model is able to account for the main cross-sectional and time series properties of local unemployment, including those documented by previous empirical work (e.g., Blanchard and Katz, 1992).

The model shows that idiosyncratic location-specific productivity is important not only for gross labor flows but also for local labor market dynamics. Specifically, it plays a key role in accounting for the negative correlation between local employment and unemployment. Moreover, both the analytical and numerical results suggest that neglecting equilibrium effects induced by trading frictions between workers and firms could lead to a conclusion that unemployment and mobility are positively related, although their true relation could well be negative. For example, in the Lucas-Prescott model, mobility and unemployment move together. In contrast, the model developed in this paper generates a negative correlation between these two variables. This is consistent with the procyclicality of regional mobility as documented in this paper.

Although this paper deals with locational unemployment and geographic mobility, its results have important implications for labor mobility across occupations and industries. Recent work by Moscarini and Thomsson (2007), Moscarini and Vella (2008) and Kambourov and Manovskii (2009) shows that occupational and industrial mobility are also procyclical. These empirical findings in the literature, along with the above results, raise the possibility that labor market dynamics of the sort modeled in this paper may also be relevant to occupational and industrial mobility.

With appropriate extensions, the model developed in this paper could also shed light on other questions of policy relevance. Given micro-data for other countries, such as those in the European Union, the model could be calibrated to Europe. The model could then be used to evaluate the extent to which lower labor mobility in Europe contributes to its higher unemployment rate. The model could also be used to examine whether the costs of 
switching sectors or training costs have a substantial impact on unemployment.

It should be noted that the model does not allow for the possibility that workers can move across local markets without going through an unemployment spell. Thus, an interesting, but both empirically and computationally harder exercise would allow for job-to-job flows across markets and examine whether they amplify the effects of local disturbances on local employment and unemployment. This type of an extension would also help in the understanding of the individual-level relationship between employment and wages in a multi-sector setting and therefore allow for a welfare evaluation of competing policies that tie benefits and moving costs to individuals' earnings.

\section{References}

Abraham, K. G., Katz, L. F., 1986. Cyclical unemployment: Sectoral shifts or aggregate disturbances? Journal of Political Economy 94, 507-522.

Alvarez, F., Shimer, R., 2011. Search and rest unemployment. Econometrica 79, 75-122.

Alvarez, F., Veracierto, M., 2000. Equilibrium search and labor market policies: A theoretical analysis, Mimeo, University of Chicago.

Andolfatto, D., Gomme, P., 1996. Unemployment insurance and labor market activity in Canada. Carnegie-Rochester Conference Series on Public Policy 44, 47-82.

Bauer, P., Lee, Y., 2005. Labor productivity growth across states. Policy Discussion Paper 16, Federal Reserve Bank of Cleveland.

Bils, M., Chang, Y., Kim, S.-B., 2011. Worker heterogeneity and endogenous separations in a matching model of unemployment fluctuations. American Economic Journal: Macroeconomics 3, 128-154.

Blanchard, O., Katz, L., 1992. Regional evolutions. Brookings Papers on Economic Activity 23, $1-61$.

Borjas, G. J., Bronars, S. G., Trejo, S. J., 1992. Self-selection and internal migration in the United States. Journal of Urban Economics 32, 159-185.

Chang, Y., Kim, S.-B., 2007. Heterogeneity and aggregation: Implications for labor-market fluctuations. American Economic Review 97, 1939-1956.

Ciccone, A., 2007. Agglomeration effects in Europe. European Economic Review 46, 213-227.

Ciccone, A., Hall, R., 1996. Productivity and the density of economic activity. American Economic Review 86, 54-70.

Coen-Pirani, D., 2010. Understanding gross worker flows across U.S. states. Journal of Monetary Economics 57, 769-784.

Dahl, G., 2002. Mobility and the return to education: Testing a Roy model with multiple 
markets. Econometrica 70, 2367-2420.

Greenwood, M. J., 1997. Internal migration in developed countries. In: Rosenzweig, M. R., Stark, O. (Eds.), Handbook of Population and Family Economics Vol. 1B. North Holland, New York, pp. 647-720.

Guvenen, F., 2009. An empirical investigation of labor income processes. Review of Economic Dynamics $12,58-79$.

Hagedorn, M., Manovskii, I., 2008. The cyclical behavior of equilibrium unemployment and vacancies revisited. American Economic Review 98, 1692-1706.

Hall, R. E., 2005. Employment fluctuations with equilibrium wage stickiness. American Economic Review 95, 50-65.

Kambourov, G., Manovskii, I., 2009. Occupational mobility and wage inequality. Review of Economic Studies 76, 731-759.

Kennan, J., Walker, J. R., 2011. The effect of expected income on individual migration decisions. Econometrica 76, 211-251.

King, M., Ruggles, S., Alexander, J. T., Flood, S., Genadek, K., Schroeder, M. B., Trampe, B., Vick, R., 2010. Integrated public use microdata series, Current Population Survey: Version 3.0 [Machine-readable database]. Minneapolis, Minnesota.

Lkhagvasuren, D., 2007. Local labor market dynamics with net and gross mobility: Implications on unemployment and wages. Ph.D. thesis, University of Rochester.

Lkhagvasuren, D., 2012. A dynamic perspective on why the more educated move more often, Mimeo, Concordia University.

Lucas, Jr., R. E., Prescott, E. C., 1974. Equilibrium search and unemployment. Journal of Economic Theory 7, 188-209.

Mortensen, D. T., Nagypál, E., 2007. More on unemployment and vacancy fluctuations. Review of Economic Dynamics 10, 327-347.

Mortensen, D. T., Pissarides, C. A., 1994. Job creation and job destruction in the theory of unemployment. Review of Economic Studies 61, 397-415.

Moscarini, G., Thomsson, K., 2007. Occupational and job mobility in the US. Scandinavian Journal of Economics 109, 807-836.

Moscarini, G., Vella, F., 2008. Occupational mobility and the business cycle. Working Paper 13819, NBER.

Pissarides, C. A., 2000. Equilibrium unemployment theory. MIT, Cambridge.

Rogerson, R., Visschers, L. P., Wright, R., 2009. Labor market fluctuations in the small and in the large. International Journal of Economic Theory 5, 125-137.

Shimer, R., 2005. The cyclical behavior of equilibrium unemployment and vacancies. American Economic Review 91, 25-49.

Topel, R. H., 1986. Local labor markets. Journal of Political Economy 94, S111-S143. 
Table 1: Variation of Unemployment

\begin{tabular}{lc}
\hline \multicolumn{2}{c}{ raw measures, CV } \\
cross-state unemployment & 0.237 \\
& $(0.039)$ \\
cyclical unemployment of the U.S. & 0.245 \\
cross-country unemployment of Europe & 0.403 \\
& $(0.039)$ \\
cross-country unemployment of Europe, & 0.355 \\
excluding Spain and Switzerland & $(0.021)$ \\
\multicolumn{2}{c}{ controlling for size and fixed effects of states } \\
CV \\
CV \\
CV $^{\mathrm{wf}}$ across states (weighted) \\
$\quad 0.204$ \\
& $(0.033)$ \\
& 0.148 \\
& $(0.034)$
\end{tabular}

Notes: Cross-state unemployment differences and aggregate unemployment were measured using the BLS's monthly state unemployment and labor force series of Jan. 1976 - May 2011. European annual unemployment data of 2003-2010 were obtained from the Organisation for Economic Co-operation and Development (http://stats.oecd.org) and include the following 18 countries: Austria, Belgium, Denmark, Finland, France, Germany, Greece, Iceland, Ireland, Italy, Luxembourg, Netherlands, Norway, Portugal, Spain, Sweden, Switzerland, and United Kingdom. Over the sample period, the average unemployment rate of these 18 European countries is 6.7 percent. 
Table 2: Labor Mobility

\begin{tabular}{lcl}
\hline variable & data & $\begin{array}{l}\text { description } \\
\text { gross mobility, } m_{t}\end{array}$ \\
$\begin{array}{c}0.028 \\
(0.006)\end{array}$ & $\begin{array}{l}\text { the number of workers who change their state of } \\
\text { residence between years } t-1 \text { and } t \text { relative to the } \\
\text { U.S. labor force at year } t\end{array}$ \\
in-migration, $m_{i, t}^{\text {in }}$ & $\begin{array}{c}0.029 \\
(0.025)\end{array}$ & $\begin{array}{l}\text { the number of workers who in-migrate to state } i \\
\text { between years } t-1 \text { and } t \text { relative to the state's } \\
\text { labor force at year } t\end{array}$ \\
out-migration, $m_{i, t}^{\text {out }}$ & $\begin{array}{c}0.029 \\
(0.016)\end{array}$ & $\begin{array}{l}\text { the number of workers who out-migrate from state } i \\
\text { between years } t-1 \text { and } t \text { relative to the state's } \\
\text { labor force at year } t \\
\text { the standard deviation of the net-migration rate, } \\
\text { std }\left(m_{i, t}^{\text {in }}-m_{i, t}^{\text {out }}\right) \text {, of an average state over time }\end{array}$ \\
\hline
\end{tabular}

Notes: The table is constructed using the Integrated Public Use Micro Sample of the CPS of 1982-1984, 1986-1994, and 1996-2010 (King et al., 2010). The sample includes adult civilians age 20-64 years who are in the labor force, but it excludes movers from foreign countries. The standard deviations are in parenthesis. See Section 2 for details. 
Table 3: Parameters of the Benchmark Model

\begin{tabular}{cll}
\hline parameter & value & description \\
\hline$\beta$ & 0.999 & the time discount factor \\
$\lambda$ & 0.0083 & the job separation rate \\
$\eta$ & 0.407 & the parameter of the matching technology \\
$\gamma$ & 0.052 & a worker's bargaining power \\
$b$ & 0.921 & flow utility of unemployment \\
$\phi$ & 0.015 & the parameter of the local technology \\
$\psi$ & 0.697 & persistence of the idiosyncratic shock \\
{$\left[k_{1-\omega} ; k_{1+\omega}\right]$} & {$[0.794 ; 1.222]$} & the vacancy creation cost \\
$\omega$ & 0.036 & volatility of the idiosyncratic shock \\
$C$ & 4.911 & the moving cost \\
$\sigma_{\epsilon}$ & 0.0047 & the conditional std.dev. of the local technology shock \\
$\rho$ & 0.988 & persistence of the local technology shock \\
\hline
\end{tabular}

Notes: The value of the weekly discount factor $\beta$ is consistent with an annual interest rate of 5 percent, i.e., $0.999 \simeq 1 / 1.05^{1 / 48}$. The values of $\lambda, \eta, \gamma, b, \phi$ and $\psi$ are set by using prior studies on aggregate unemployment and labor income. The value of $k_{1+\omega}$ is determined by equation (8). The values of the remaining five parameters, $k_{1-\omega}, \omega, C, \sigma_{\epsilon}$ and $\rho$, are chosen by targeting the data moments listed in the upper panel of Table 4. 
Table 4: Main Results

\begin{tabular}{|c|c|c|c|c|}
\hline moment & data & benchmark & low $\omega$ & high $\omega$ \\
\hline \multicolumn{5}{|c|}{ calibration targets } \\
\hline aggregate unemployment, $\bar{r}$ & 0.057 & 0.057 & 0.055 & 0.056 \\
\hline gross mobility, $\bar{m}$ & 0.028 & 0.028 & 0.028 & 0.028 \\
\hline net mobility, $\sigma_{m}$ & 0.011 & 0.011 & 0.070 & 0.010 \\
\hline volatility of per-worker output, $\sigma_{y}$ & 0.027 & 0.027 & 0.027 & 0.027 \\
\hline persistence of per-worker output & 0.655 & 0.656 & 0.644 & 0.653 \\
\hline \multicolumn{5}{|c|}{ predictions } \\
\hline unemp.rate differences, $\mathrm{CV}^{\mathrm{wf}}$ & 0.148 & 0.156 & 0.168 & 0.152 \\
\hline persistence of unemp. rate & 0.994 & 0.989 & 0.961 & 0.988 \\
\hline overall market tightness & $0.539-0.634$ & 0.616 & 0.661 & 0.627 \\
\hline monthly job-finding rate & $0.388-0.773$ & 0.463 & 0.476 & 0.464 \\
\hline volatility of emp. growth, $\operatorname{std}\left(\Delta e_{t}\right)$ & 0.012 & 0.014 & 0.066 & 0.013 \\
\hline volatility of unemp. growth, $\operatorname{std}\left(\Delta u_{t}\right)$ & 0.096 & 0.114 & 0.180 & 0.111 \\
\hline $\operatorname{corr}\left(\Delta u_{t}, \Delta e_{t}\right)$ & $-0.279^{(\mathrm{a})}$ & $-0.676^{(\mathrm{a})}$ & $0.077^{(\mathrm{b})}$ & $-0.719^{(\mathrm{a})}$ \\
\hline
\end{tabular}

Notes: Per-worker output refers to the ratio of total output produced in the local market over a given year to its annual employment. Overall market tightness is defined as the ratio of the total number of vacancies in the economy to aggregate unemployment. In the model, annual employment and unemployment growth is defined as $\Delta e_{t}=\log \left(E_{t} / E_{t-1}\right)$ and $\Delta u_{t}=\log \left(U_{t} / U_{t-1}\right)$, where $E_{t}$ and $U_{t}$ denote local employment and unemployment at year $t$, respectively. However, in the data, the aggregate effects are controlled for by considering the following differences: $\Delta e_{i, t}=\log \left(E_{i, t} / E_{i, t-1}\right)-\log \left(E_{t}^{\mathrm{US}} / E_{t-1}^{\mathrm{US}}\right)$ and $\Delta u_{i, t}=$ $\log \left(U_{i, t} / U_{i, t-1}\right)-\log \left(U_{t}^{\mathrm{US}} / U_{t-1}^{\mathrm{US}}\right)$, where $E_{i, t}$ and $U_{i, t}$ denote employment and unemployment of state $i$ at year $t$, while $E_{t}^{\mathrm{US}}$ and $U_{t}^{\mathrm{US}}$ denote aggregate employment and unemployment at time $t$. (If the aggregate effect is not controlled for, $\operatorname{corr}\left(\Delta u_{t}, \Delta e_{t}\right)$ is even stronger at -0.701.) Superscripts (a) and (b) denote the correlation coefficients of the significance levels of 0.01 and 0.05 , respectively. 
Table 5: Univariate Autoregressive Processes of Employment and Unemployment

\begin{tabular}{lcc}
\hline & $\begin{array}{c}\text { log employment } \\
\text { growth, } \Delta e\end{array}$ & $\begin{array}{c}\text { unemployment } \\
\text { rate, } r\end{array}$ \\
\hline \multicolumn{3}{c}{ regression results } \\
one lag & 0.444 & 0.832 \\
two lags & $(0.031)$ & $(0.042)$ \\
& -0.170 & -0.211 \\
three lags & $(0.034)$ & $(0.043)$ \\
& -0.033 & \\
four lags & $(0.034)$ & \\
& -0.007 & \\
root mse & $(0.032)$ & 0.006 \\
& 0.013 & \\
year 1 & implied impulse responses & \\
year 2 & 1.000 & 1.000 \\
year 3 & 1.444 & 0.832 \\
year 4 & 1.471 & 0.481 \\
year 5 & 1.374 & 0.225 \\
year 10 & 1.304 & 0.086 \\
year 20 & 1.306 & -0.002 \\
\end{tabular}

Notes: This table estimates univariate models of the employment growth and the unemployment rate using simulated data and traces the implied impulse responses. The specifications of the univariate models are those used by Blanchard and Katz (1992) to analyze statelevel data. The upper panel displays the coefficients of lagged dependent variables (the log employment growth and the unemployment rate) and the root mean squared errors of the regressions. The standard errors of the coefficients are in parentheses. The lower panel shows the implied impulse responses of log employment and the unemployment rate to innovation of 1 . It can be seen that both the coefficients and the impulse responses are remarkably consistent with those in Table 1 of Blanchard and Katz (1992). 
Table 6: Impact of an Aggregate Productivity Shock

\begin{tabular}{lc}
\hline the aggregate unemployment rate, $\bar{r}$ & $-7.7 \%$ \\
the mobility rate, $\bar{m}$ & $+51.3 \%$ \\
the average wage, $\bar{w}$ & $+1.1 \%$ \\
the total number of vacancies, $\bar{v}$ & $+10.0 \%$ \\
\hline
\end{tabular}

Notes: The table summarizes the impact of a permanent increase in aggregate productivity on the key aggregate variables of the benchmark model. It shows that an increase in aggregate productivity lowers unemployment and raises labor mobility, which is consistent with the observed procyclicality of gross mobility shown in Figure 4. 
Figure 1: Mobility Decision

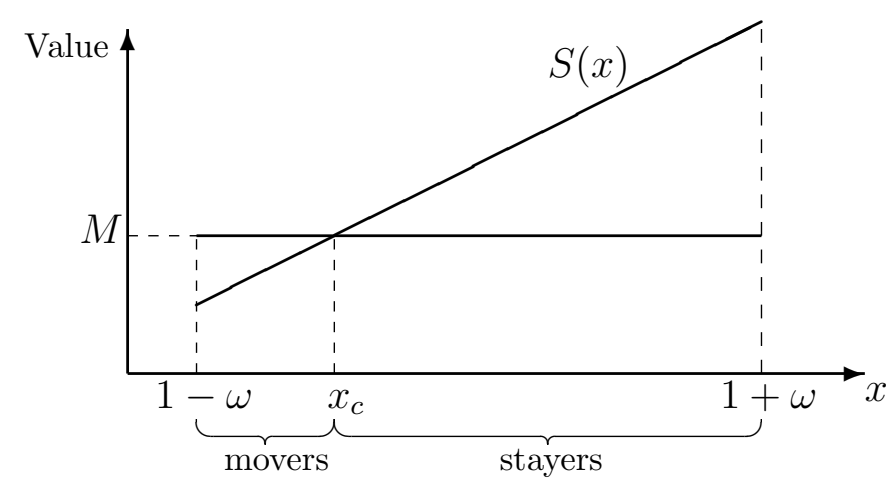

Notes: The figure shows who moves and who stays behind. $S(x)$ is the value to a worker of searching for a job on the current island when his or her location-specific productivity for that island is $x$. $M$ is the value of leaving the island to look for a better job elsewhere. Unemployed workers with location-specific productivity less than $x_{c}$ leave their current island and those whose productivity level is equal to or higher than $x_{c}$ stay. 
Figure 2: Impact of a Local Technology Shock

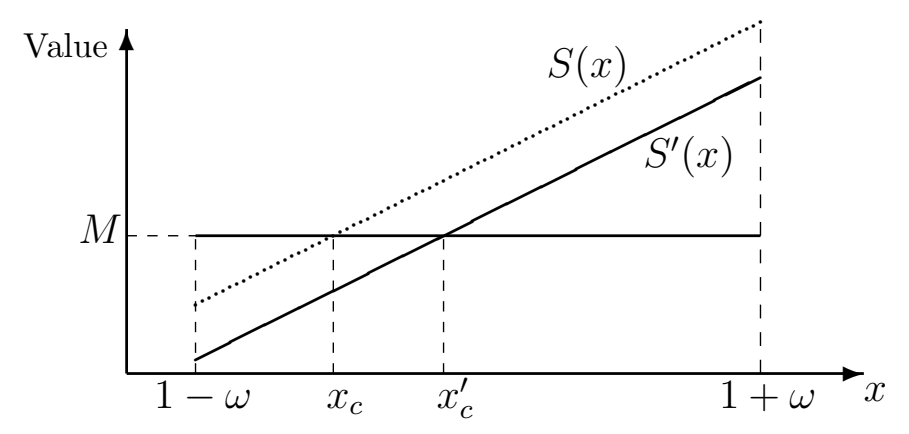

Notes: This figure shows the impact of an unanticipated adverse technology shock to an island. $S(x)$ and $S^{\prime}(x)$ denote the values before and after the realization of the shock, respectively. If there is insufficient dispersion $(\omega)$ in location-specific productivity and if the adverse local technology shock is large, it is possible that $S^{\prime}(x)<M$ for all $x$. This means that if the dispersion $\omega$ is low, an adverse technology shock can reduce local unemployment while generating a counterfactual positive correlation between local employment and unemployment. 
Figure 3: Employment Shock of Blanchard and Katz (1992)

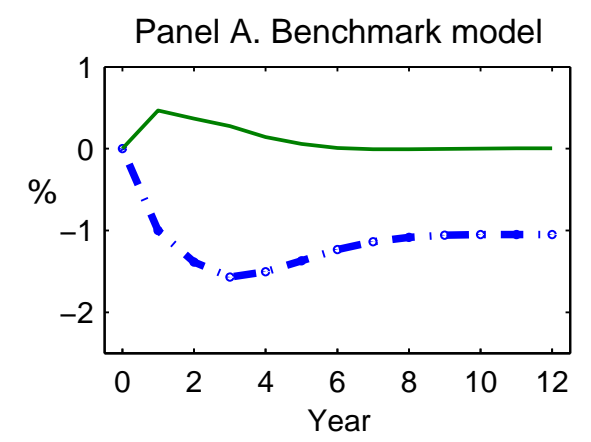

Panel B. Economy with a low productivity dispersion

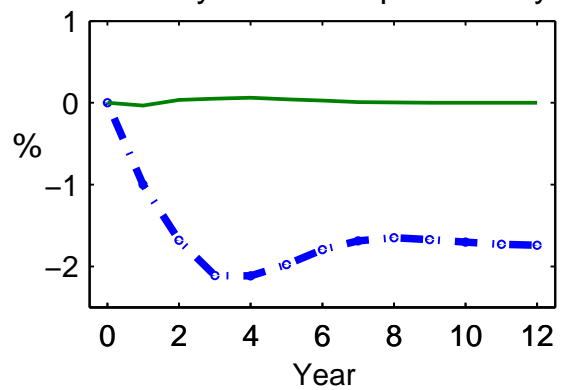

Panel C. Economy with a high productivity dispersion

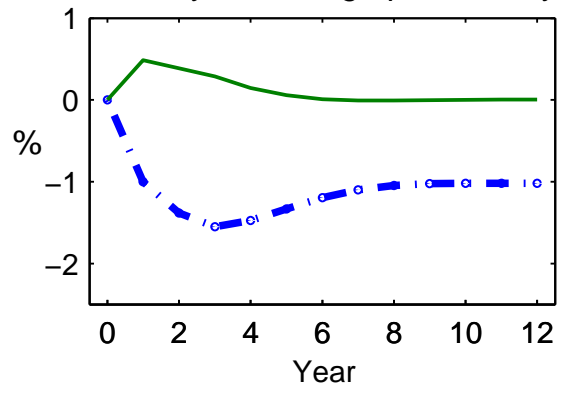

Notes: This figure traces the joint responses of the local unemployment rate (solid curve) and local employment (dashed curve) of the model economy to an adverse employment shock considered by Blanchard and Katz (1992). See Section 5 for further details. 
Figure 4: Aggregate Unemployment and Labor Mobility
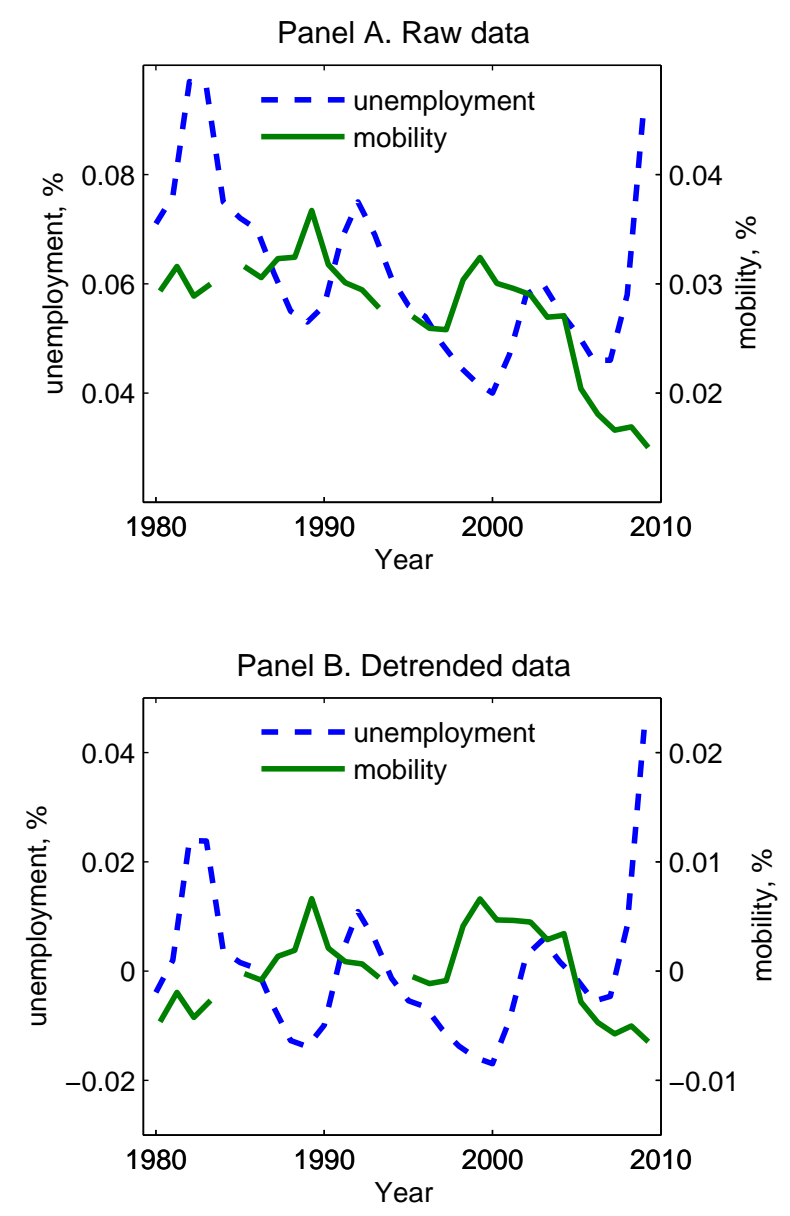

Notes: The upper panel plots aggregate unemployment and gross inter-state mobility in the U.S. over the period 1980 through 2009 (the CPS does not record inter-state mobility for the years 1985 and 1995). The lower panel plots the deviations of these two series from their respective linear trends. Over the sample period, the correlation coefficient between the two detrended series is -0.58 at the 0.01 significance level. 


\author{
Supplementary Materials \\ to "Big Locational Unemployment Differences \\ Despite High Labor Mobility" \\ Damba Lkhagvasuren \\ Concordia University and CIREQ
}

\title{
A Data appendix
}

This appendix provides further empirical details. It starts by showing that an inter-state move is more likely to be made for work-related reasons.

\section{A.1 Reasons for moving in the CPS}

The CPS records the reasons for moving for those who moved during the past year. The question offers 17 response categories, ordered under four main groupings: family, employment, housing, and other reasons. Table A.1 summarizes responses to this question. It shows that among inter-state movers, the highest percentage of people say that they move for employment-related reasons followed by family- and housing-related reasons. For white male workers, the percentage of employment-related reasons is even higher. Moreover, since inter-state moves are frequently accompanied by a change in employment status or a new employment relation, it seems reasonable to think that, to a certain extent, moves that are reported as unrelated to employment are also influenced by economic factors.

Clearly, some of the residential moves are recorded as an inter-state move. For example, an individual could be moving from Jersey City, NJ to New York, NY for family-related reasons without actually changing his or her labor market. Thus, reasons for moving between neighboring states may differ from reasons for moving between labor markets. One way to reduce the effects of neighboring states is to consider longer distance moves. Table A.1 shows that the relative frequency of employment-related moves increases with the moving distance and thus confirms that most of the moves between different local markets are made 
Table A.1: Distribution of Movers by Reason for Moving, 1999-2009

\begin{tabular}{lcc|cc}
\hline & \multicolumn{2}{c|}{ between states } & \multicolumn{2}{c}{$\begin{array}{c}\text { between census } \\
\text { divisions }\end{array}$} \\
\cline { 2 - 5 } reason for moving & all & $\begin{array}{c}\text { white } \\
\text { male }\end{array}$ & all & $\begin{array}{c}\text { white } \\
\text { male }\end{array}$ \\
\hline employment & $45.3 \%$ & $51.6 \%$ & $53.8 \%$ & $59.2 \%$ \\
family & $23.5 \%$ & $20.2 \%$ & $22.2 \%$ & $19.0 \%$ \\
housing & $20.2 \%$ & $18.3 \%$ & $11.3 \%$ & $10.5 \%$ \\
other & $11.0 \%$ & $9.9 \%$ & $12.7 \%$ & $11.3 \%$ \\
\hline
\end{tabular}

Notes: The percent distribution of movers of the same group and the same type of moves is presented by a column in the table. Reasons labeled "other" include attending or leaving college, change of climate and health. The main sample includes adult civilians ages 20-64 who work for wages or salary. (When the sample is restricted to workers who are between 28 and 60 years of age, the frequency of employment-related reasons is even higher than those in the table.)

for employment reasons.

\section{A.2 More on cross-state unemployment differences}

This appendix provides further facts on cross-state unemployment differences. It shows that the differences remain large under various specifications.

\section{A.2.1 Persistence}

Here I quantify the effect of transitory shocks on local unemployment differences. For this purpose, consider the following autoregressive process for the relative unemployment rate of state $i$ :

$$
r_{i, t+1}^{\mathrm{R}}=\bar{r}_{i}^{\mathrm{R}}\left(1-\rho_{r}\right)+\rho_{r} r_{i, t}^{\mathrm{R}}+\tilde{\varepsilon}_{i, t+1},
$$

where $\rho_{r}$ is the monthly autocorrelation of the relative unemployment rate, $\bar{r}_{i}^{\mathrm{R}}$ is the state fixed effect, and $\tilde{\varepsilon}_{i, t}$ is an i.i.d transitory innovation with zero mean and variance $\sigma_{r}^{2}$. Then, the stationarity of the relative unemployment rate Blanchard and Katz (1992) implies that

$$
\mathrm{CV}^{2}=\rho_{r}^{2} \mathrm{CV}^{2}+\sigma_{r}^{2} .
$$


Between Jan. 1976 and May 2011, monthly autocorrelation of the relative state unemployment rate averages 0.9938 with a standard deviation of 0.0057 . A weighted average of these autocorrelation coefficients using the labor share of each state as the weight gives $\rho_{r}=0.9940 .^{25}$ This value, along with equation (A.2), implies that approximately 98.8 percent $\left(=0.994^{2} \times 100 \%\right)$ of the variance $\mathrm{CV}^{2}$ is attributable to the persistence of local unemployment (even after controlling for state fixed effects), while the remaining 1.2 percent is due to monthly transitory effects.

\section{A.2.2 Differences by proximity}

It is possible that unemployment differences between neighboring states are much smaller than differences between distant states. To examine whether this is the case, the effect of the proximity of local labor markets is measured using unemployment differences between larger sub-national geographic units: census regions and census divisions. In particular, the proportion of cross-state unemployment differences attributable to differences within these larger geographic groups is calculated using the following decomposition:

$$
\mathrm{CV}^{2}=\mathrm{BG}+\mathrm{WG}
$$

where BG denotes between-group differences and WG within-group differences. Over the sample period, on average, only 17 percent of the total cross-state variance $\mathrm{CV}^{2}$ is due to differences between the census regions, and the remaining 83 percent is due to differences between states that belong to the same census region. For census divisions, as expected, the proportion of within-group differences is a little lower and averages 55 percent. So, withingroup differences dominate between-group differences in both cases. These findings suggest that cross-sectional unemployment differences are substantial even between proximate states.

\footnotetext{
${ }^{25}$ This suggests that local unemployment differences are as persistent as aggregate unemployment. Using a quarterly autocorrelation of aggregate unemployment of 0.87 reported by Hagedorn and Manovskii (2008), monthly autocorrelation of aggregate unemployment is $0.955\left(=0.87^{1 / 3}\right)$.
} 


\section{A.2.3 Differences by age}

As shown in Table A.2, young workers move more frequently than their older cohorts. Therefore, it is possible that cross-state differences in unemployment between local labor markets are smaller among the younger labor force, while unemployment differences are largely generated by less mobile prime-age and older workers. However, Table A.3 shows that the cross-sectional variation of unemployment remains large even after controlling for age.

Table A.2: Mobility by Age and Education

\begin{tabular}{lccc}
\hline age (yrs.) & no-college & college & all \\
\hline $20-34$ & 0.037 & 0.058 & 0.044 \\
$35-54$ & 0.017 & 0.021 & 0.018 \\
$55-64$ & 0.011 & 0.014 & 0.012 \\
\hline
\end{tabular}

Notes: The table displays inter-state mobility by age and education using the CPS of 1981-2010. The sample includes adult civilians ages 20-64 who are in the labor force. The education category "College" includes individuals who have a college degree or above.

Table A.3: Cross-State Unemployment Differences by Age

\begin{tabular}{lc}
\hline age (yrs.) & $\mathrm{CV}$ \\
\hline $20-34$ & 0.21 \\
$35-54$ & 0.25 \\
$55-64$ & 0.40 \\
\hline
\end{tabular}

Notes: The numbers are calculated using state unemployment series by main age group. These series were issued by the BLS for 1978-2004 and are now discontinued. The data were provided by Robert Shimer. See Shimer (2001) for a further description of these series.

One could also look at cross-state differences by education. However, to my knowledge, there are no reliable data on unemployment by education at the local level. Nevertheless, using the facts that overall unemployment is high among less educated workers and that unemployment differences remain large among young workers (see Table A.3), it can be seen that locational unemployment differences among less educated young workers are high, despite their high mobility shown in Table A.2. 


\section{A.3 Unemployment differences between movers and stayers}

This section examines how unemployment and mobility are related at the individual level. Specifically, it measures how unemployment differs by annual mobility status using the CPS of 1982-2010. To focus on mobility that is not affected by schooling and retirement, the sample is restricted to those who are between 28 and 60 years of age and in the civilian labor force. In the sample, unemployment among movers and non-movers is 10.0 and 4.1 percent, respectively. This means that recent movers are 2.5 times more likely to be unemployed than the rest of the labor force.

Since both unemployment and mobility differ considerably across age and education of the labor force, one might be concerned that the bulk of the unemployment gap between movers and non-movers could be explained by age and education. To examine whether this is the case, the following regression is considered for two main education levels, high school and college:

$$
h_{i, j, t}=\delta D_{i}+\tilde{b} X_{i, j, t}+\tilde{\epsilon}_{i, j, t}
$$

where $h_{i, s, t}$ is a dummy for whether person $i$ who is living in state $j$ in year $t$ is unemployed, $D_{i}$ is a dummy for whether the person is a mover, and $X_{i, j, t}$ is a set of controls such as state and year effects, dummies for the person's sex and race and a quartic polynomial for the person's age. The results displayed in Table A.4 show that among observationally identical workers, movers are still more likely to be unemployed than non-movers.

These results are consistent with the assumption that movers are unemployed. In fact, in the heterogeneous agent model, unemployment among workers who arrived at their current location within the last 48 weeks is 18.9 percent, while unemployment among stayers is 5.3 percent. Thus, in the model, movers are $3.6(=18.9 / 5.3)$ times more likely to be unemployed than stayers, as opposed to $2.3(=1+7.2 / 5.6)$ to $2.7(=1+4.4 / 2.6)$ times as likely in the data.

Clearly, if on-the-job search is allowed, the model can generate lower unemployment among movers. One can also introduce heterogeneity along the lines of ex-ante unobserved 
Table A.4: Unemployment by Mobility Status (\%)

\begin{tabular}{lcc}
\hline & high school & college \\
\hline unemployment among movers & 12.8 & 6.6 \\
unemployment among stayers & 5.6 & 2.6 \\
difference, $\delta$ & 7.183 & 4.345 \\
& $(0.287)$ & $(0.223)$ \\
\hline
\end{tabular}

Notes: The employment and mobility statuses are measured from the CPS of 1982-2010. The unemployment rates and their differences are reported in percentages. Standard errors are in parenthesis. The labels high school and college denote, respectively, high school diploma and a bachelor's degree. $\delta$ measures unemployment of movers relative to that of stayers while controlling for individuals' observed characteristics as well as year and state effects by using equation (A.4). The standard errors are in parenthesis.

ability, moving cost and the leisure value to target differences between movers and stayers. In practice, it is difficult, if not impossible, to obtain the reliable data required to quantify the relative effect of these elements.

On the other hand, the smaller mover-stayer unemployment gap in the data can be partially attributed to inconsistency between the time at which workers move and the time at which their unemployment and mobility statuses are recorded in the data. Specifically, the CPS records an individual's mobility status in March. However, it is well known that geographic mobility peaks in the summer. Therefore, many unemployed workers who move in the summer will already have found a job by the following March, suggesting that the actual unemployment gap between movers and stayers could be higher than what is measured in Table A.4. Nevertheless, the large unemployment gap between movers and stayers in the model is comparable with that in the data.

\section{A.4 Local productivity}

Annual per-worker productivity by state for 1974 through 2004 was obtained from Bauer and Lee (2005), who construct these series using data on gross domestic product by state released 
by the Bureau of Economic Analysis (BEA) ${ }^{26}$ Local productivity is defined as the logarithm of per-worker gross state product minus the logarithm of per-worker gross domestic product of the entire U.S. In the data, there is a substantial variation in the relative growth rates of productivity across states. Specifically, during the sample period, the productivity of some states has steadily grown at 0.8 percent per year relative to the national average, while the productivity of some states has declined, with rates of -0.8 percent relative to the national average. Since relative unemployment exhibits no trend (Blanchard and Katz, 1992), the relative productivity is de-trended using state-specific linear trends. Then, for each state, the standard deviation and annual autocorrelation of these de-trended shifts are calculated. The weighted average of these standard deviations using the labor share of each state as the weight is 0.028 , while the weighted average of state-specific annual autocorrelation is 0.657 . According to Ciccone and Hall (1996), some states in which natural resources are sufficiently important for their economic activity, gross state product per worker gives extremely volatile output measures. When Alaska, Louisiana, West Virginia and Wyoming are excluded, as in Ciccone and Hall (1996), the volatility and persistence measures become 0.027 and 0.655, respectively.

For comparison purposes, I also look at the cyclical variation of per-worker gross domestic product of the entire U.S. The standard deviation of the cyclical component of per-worker product of the U.S. is 0.024 , and its annual autocorrelation is 0.756 . (The latter implies a quarterly autocorrelation of 0.933.) These numbers are very close to those measured from hourly productivity (e.g., Shimer (2005) and Bils, Chang and Kim (2011)), and thus reassuring that gross state product per worker provides a reasonable measure of labor productivity.

\section{B Details of the homogeneous islands model}

This appendix presents further details of the homogeneous islands model. Specifically, it provides the derivation of the analytical results in Sections 3.3 and 3.4.

\footnotetext{
${ }^{26}$ The BEA's estimation methodology of gross domestic product can be found at http://bea.doc.gov/ regional/gsp/help/.
} 


\section{B.1 Stayers and firms}

Let $\bar{H}(x)=\int H\left(x^{\prime}\right) Q_{u}\left(d x^{\prime} \mid x\right)$. Then, equation (1) can be written as

$$
W(x)=\frac{w+\beta \lambda \bar{H}(x)}{\tilde{\lambda}} .
$$

Using the free-entry condition and equation (5),

$$
J(x)=\frac{x-w}{\tilde{\lambda}}=\frac{k_{x}}{\beta \alpha(q(x))} .
$$

Since $W(x)+J(x)$ is independent of $w$ and $V(x)=0$, the solution to the maximization problem in equation (6) satisfies

$$
W(x)-S(x)=\frac{\gamma}{1-\gamma} J(x) .
$$

Combining equations (B.2) and (B.3),

$$
W(x)-S(x)=\frac{\gamma}{1-\gamma} \frac{k_{x}}{\beta \alpha(q(x))} .
$$

Inserting the latter into equation (2) for $W(x)-S(x)$, one can obtain

$$
(1-\beta) S(x)-b=\frac{\gamma}{1-\gamma} \frac{k_{x}}{q(x)} .
$$

The last equation establishes how the queue length $q(x)$ and the value $S(x)$ are related at the equilibrium for each $x$. Inserting equations (1) and (B.5) into equation (2) for $W(x)$ and $S(x)$, respectively, yields equation (8).

\section{B.2 Prohibitive moving cost}

Given $H_{0}=\int H(x) d G(x)$, the value of leaving the current island is

$$
M=b-C+\beta H_{0} .
$$

If no one moves, the moving cost is so high that

$$
M \leq S(1-\omega) .
$$

Since $\max \{S(x), M\}=S(x), \int S(x) d G(x)=S(1)$. Then, it follows that $H_{0}=\frac{\zeta_{0}+\zeta_{2}}{1-\zeta_{1}}$ and $S(1-\omega)=\zeta_{0}-\frac{\beta-\zeta_{1}}{1-\zeta_{1}}\left(\zeta_{0}+\zeta_{2}\right)+\zeta_{2} x$. Inserting the last two equations into equation (B.7), it can be seen that there will be no mobility if $C \geq C_{\max }$, where

$$
C_{\max }=b+\frac{\beta-\zeta_{1}}{1-\zeta_{1}}\left(\zeta_{0}+\zeta_{2}\right)-\zeta_{2}(1-\omega)-\zeta_{0} .
$$




\section{B.3 Mover's problem}

If $C<C_{\max }$, there exists $1-\omega<x_{c}<1+\omega$ such that $S\left(x_{c}\right)=M$. Then, using equations (10) and (B.6),

$$
H_{0}=\frac{\zeta_{2} x_{c}+\zeta_{0}-b+C}{\beta-\zeta_{1}}
$$

On the other hand,

$$
H_{0}=\zeta_{0}+\zeta_{1} H_{0}+\zeta_{2}\left(\frac{x_{c}^{2}-(1-\omega) x_{c}}{2 \omega}+\int_{x_{c}}^{1+\omega} x d G(x)\right) .
$$

Taking the integration and combining the result with equation (B.9) yields a quadratic equation for $x_{c}$. Solving the equation while taking into account the effect of the moving cost will yield equation (11).

\section{B.4 Mobility and unemployment}

Let $h$ denote an individual's employment status: $h=1$ if unemployed and $h=0$ if employed. Let $\mu(h, x)$ denote the measure of individuals residing on an island at the moment following the realization of idiosyncratic shocks. Since both newly unemployed and newly arrived workers draw their productivity shocks from the same distribution, some of the newly arrived workers will decide to leave their new location again. Therefore, the number of movers is given by

$$
m=\left(\lambda(1-\psi) \int_{x_{c}}^{1+\omega} \mu(0, x) d x+m\right) G\left(x_{c}\right) .
$$

Then, the total number of employed workers is given by

$$
\int_{x_{c}}^{1+\omega} \mu(0, x) d x=\frac{m}{\lambda(1-\psi)} \frac{1-G\left(x_{c}\right)}{G\left(x_{c}\right)} .
$$

Furthermore, in equilibrium, the flows into and out of employment must equal:

$$
f\left(q_{1}\right) \int_{x_{c}}^{1+\omega} \mu(1, x) d x=\lambda \int_{x_{c}}^{1+\omega} \mu(0, x) d x .
$$

Combining the latter with equation (B.11), the total number of stayers is given by

$$
\int_{x_{c}}^{1+\omega} \mu(1, x) d x=\frac{m}{f\left(q_{1}\right)(1-\psi)} \frac{1-G\left(x_{c}\right)}{G\left(x_{c}\right)} .
$$


Normalizing the local labor force to one,

$$
\bar{m}+\frac{\bar{m}}{\lambda(1-\psi)} \frac{1-G\left(x_{c}\right)}{G\left(x_{c}\right)}+\frac{\bar{m}}{f\left(q_{1}\right)(1-\psi)} \frac{1-G\left(x_{c}\right)}{G\left(x_{c}\right)}=1 .
$$

Solving the latter for $\bar{m}$ yields the equilibrium mobility rate in equation (13). Finally, using the total number of movers and stayers, one can arrive at equation (14).

\section{Details of the heterogeneous islands model}

This appendix provides the definition of the equilibrium of the heterogeneous islands model as well as the numerical details. It also discusses some of the modeling choices.

\section{C.1 Definition of the equilibrium}

The equilibrium consists of a set of value functions, $\{H, S, W, M, V, J\}$, a mobility decision function, $\Omega$, wages $w$, the measures, $\{\mu, m, v\}$, the queue length, $q$, a law of motion, $\Gamma$, and an economy-wide distribution, $\Phi$, such that

1. employed: given $\Gamma, H$ and $w$, the value function $W(x, \mathbf{s})$ solves equation (17);

2. stayer: given $q, \Gamma, \Phi, H$ and $W$, the value function $S(x, \mathbf{s})$ solves equation (18);

3. mover: given $H$ and $\Phi$, the value function $M$ solves equation (19);

4. unemployed: the decision rule $\Omega(x, \mathbf{s})$ and the value function $H(x, \mathbf{s})$ are consistent with $S(x, \mathbf{s})$ and $M$;

5. matched firm: given $\Gamma$ and $w$, the value function $J(x, \mathbf{s})$ solves equation (20);

6. unmatched firm: given $\Gamma, J$, and $q$, the value function $V(x, \mathbf{s})$ solves equation (21);

7. free entry: $V(x, \mathbf{s})<0$ if $v(x, \mathbf{s})=0$, or $V(x, \mathbf{s})=0$ if $v(x, \mathbf{s})>0$;

8. bargaining: given $S, W, J$ and $V, w(x, \mathbf{s})$ solves equation (22);

9. consistency of $q: q(x, \mathbf{s}) v(x, \mathbf{s})=\Omega(x, \mathbf{s}) \mu(0, x)$; and

10. consistency of $\Gamma$ and $\Phi$ : equations (16), (23) and (24) hold.

\section{C.2 Perceived law of motion}

Solving for the equilibrium involves the following two interrelated tasks: (i) finding decisions of workers and firms conditional on the local labor market condition $\mathbf{s}=(z, \mu)$, the law 
of motion $\Gamma$, and the stationary distribution of the islands $\Phi$; and (ii) finding the law of motion $\Gamma$, and the stationary distribution $\Phi$, that are consistent with workers' and firms' behavior. The model is solved using the method of Krusell and Smith (1998), by extending its application to a multi-sector search setting.

The assumption on $\Gamma$ is that the next period's employment is a function of the current technology shock, employment and labor force. The function will be referred to as the perceived law of motion. Given $M, \bar{m}$ and the perceived law of motion, the local labor market equilibrium is solved. Using the equilibrium, the behavior of a measure one of workers across a continuum of islands is simulated. Numerical iteration on the perceived law of motion is performed until $M$ and $\bar{m}$ become consistent with the stationary distribution $\Phi$.

The specification of the perceived law of motion for employment is given by

$$
p^{\prime}=\kappa_{11}+\kappa_{12} z+\kappa_{13} p+\kappa_{14} \ell,
$$

where $p=-\phi \ln \tilde{E}$ and $\ell=\ln L$. Since firms and workers have to forecast employment in the subsequent periods, they also need to forecast the future labor force. For this purpose, it is assumed that the log-labor force evolves according to the following equation:

$$
\ell^{\prime}=\kappa_{21}+\kappa_{22} z+\kappa_{23} \ell .
$$

Under the benchmark parameterization, the perceived law of motion is given by:

$$
p^{\prime}=0.00061-0.00061 z+0.9039 p-0.0014 \ell
$$

subject to

$$
\ell^{\prime}=-0.00808+0.00806 z+0.99857 \ell
$$

The accuracy of the approximation is measured by $R^{2}=1-\frac{\sum_{t=1}^{T}\left(Y_{t}-\hat{Y}_{t}\right)^{2}}{\sum_{t=t_{0}}^{T}\left(Y_{t}-\bar{Y}\right)^{2}}$, where $Y_{t}$ is the simulated value of $p$ (or $\ell$ ) at $t, \bar{Y}$ is the mean of $Y_{t}$ over time and $\hat{Y}_{t}$ is the predicted value of $Y_{t}$ using the perceived law of motion and the simulated values of $t-1$. The model is simulated for 50000 periods. The values for $R^{2}$ associated with regression equations (C.3) and (C.4) are, respectively, 0.99997 and 0.99998. So, the aggregate approximation method 
works well for the model in the sense that forecasting errors that result from omission of the other moments of the measure $\mu$ are negligible.

Given equations (C.1) and (C.2), the local labor market equilibrium is obtained using value function iteration. The stochastic process of $z$ is approximated using a 3-point Markov chain. The grid points and the transition matrix of the Markov chain are calculated using the method of Rouwenhorst (1995). ${ }^{27}$ The discrete grids of $p$ are $\left\{0, \pm \frac{\sigma_{z}}{3}, \pm \frac{2 \sigma_{z}}{3}, \pm \frac{3 \sigma_{z}}{2}\right\}$ where $\sigma_{z}$ is the standard deviation of $z$. The grids of $\ell$ are given by the following five equally-spaced points: $\{0, \pm 0.1, \pm 0.2\}$.

Having many grid points along the idiosyncratic shock, $x$, is essential for solving the model. If a sufficiently fine grid is not maintained along $x$, the size of the local labor force and employment will evolve in a stepwise pattern due to heavier mass points inherited from the coarser grid. The latter, in turn, will make it difficult to retrieve a meaningful law of motion for $p$ and $\ell$. On the other hand, the combination of the large state space and the two infinite dimensional objects $(\Gamma$ and $\Phi)$ makes it impossible to carry out the entire computation with a large number of grid points for $x$. For this reason, two types of grid points are used. First, the value functions and the decision rules are solved on a coarser grid of 15 equispaced grid points for $x$. Then, the values associated with a finer grid of 121 equispaced points of $x$ are calculated by applying three-dimensional linear interpolation (along $x, p$ and $\ell$ ) to the values associated with the coarser grid. Once the decision rules for the finer grid are obtained, simulating the economy amounts to simple matrix manipulation.

\section{C.3 Numerical algorithm}

The key steps of the numerical algorithm are as follows:

1. Guess the mobility rate, $\hat{\bar{m}}^{0}$, and the value of moving, $\hat{M}^{0}$.

2. Guess the coefficients of equations (C.1) and (C.2). Let $\hat{\kappa}_{1}^{0}=\left\{\hat{\kappa}_{11}^{0}, \hat{\kappa}_{12}^{0}, \hat{\kappa}_{13}^{0}, \hat{\kappa}_{14}^{0}\right\}$ and $\hat{\kappa}_{2}^{0}=\left\{\hat{\kappa}_{21}^{0}, \hat{\kappa}_{22}^{0}, \hat{\kappa}_{23}^{0}\right\}$ denote the values of the coefficients. A good initial guess may

\footnotetext{
${ }^{27}$ Galindev and Lkhagvasuren (2010) show that the method outperforms other commonly used discretization methods for high persistence.
} 
come from the economy with no local technology shock, i.e., $\hat{\kappa}_{1}^{0}=\{0,0,1,0\}$ and $\hat{\kappa}_{2}^{0}=\{0,0,1\}$.

3. Given $\hat{\kappa}_{1}^{0}, \hat{\kappa}_{2}^{0}$ and $\hat{M}^{0}$, solve for the equilibrium queue lengths and the mobility decision. This step involves the following tasks:

(a) Given the coarser grid points along $x$, guess $H^{\dagger}, S^{\dagger}$ and $W^{\dagger}$. (The values indexed by $\dagger$ and $\ddagger$ denote the values on the coarser and finer grids, respectively.)

(b) Given the parametric law of motion, calculate the value of the matched firm, $J^{\prime}$, as a function of wage, $w^{\prime}$.

(c) Find $w^{\dagger}$ and $q^{\dagger}$ for each point of the coarser grid.

(d) Using $w^{\dagger}$ and $q^{\dagger}$, obtain new values for $H^{\dagger}, S^{\dagger}$, and $W^{\dagger}$. Repeat steps (a) through (d) until the values of two consecutive iterations are close enough for each function and each grid point.

(e) By applying numerical interpolation to $H^{\dagger}, S^{\dagger}$ and $q^{\dagger}$, generate the job-finding rate $f\left(q^{\ddagger}\right)$ and the mobility decision $\Omega^{\ddagger}$ on the finer grid of $x$.

4. Using $\Omega^{\ddagger}, f\left(q^{\ddagger}\right)$, and $\hat{m}^{0}$, simulate the economy for a large number of periods.

5. Estimate the coefficients of equations (C.1) and (C.2) using the simulated data. Let the estimates be $\hat{\kappa}_{1}^{1}=\left\{\hat{\kappa}_{11}^{1}, \hat{\kappa}_{12}^{1}, \hat{\kappa}_{13}^{1}, \hat{\kappa}_{14}^{1}\right\}$ and $\hat{\kappa}_{2}^{1}=\left\{\hat{\kappa}_{21}^{1}, \hat{\kappa}_{22}^{1}, \hat{\kappa}_{23}^{1}\right\}$. If $\hat{\kappa}^{0}=\left\{\hat{\kappa}_{1}^{0}, \hat{\kappa}_{2}^{0}\right\}$ and $\hat{\kappa}^{1}=\left\{\hat{\kappa}_{1}^{1}, \hat{\kappa}_{2}^{1}\right\}$ are close enough, go to the next step; otherwise revise the coefficients by setting $\hat{\kappa}^{0}=\tilde{\gamma} \hat{\kappa}^{0}+(1-\tilde{\gamma}) \hat{\kappa}^{1}$ for some $0<\tilde{\gamma}<1$ and go to Step 3 .

6. Using the simulated data, calculate the mobility rate, $\hat{\bar{m}}^{1}$, and the value of leaving the current island, $\hat{M}^{1}$. If $\hat{\bar{m}}^{1}$ and $\hat{M}^{1}$, are close enough to $\hat{\bar{m}}^{0}$ and $\hat{M}^{0}$, respectively, stop. Otherwise, update the values of $\hat{\bar{m}}^{0}$ and $\hat{M}^{0}$ and go to Step 2 . 


\section{C.4 Allowing for endogenous separation}

If the local technology shock of an island declines abruptly, there can be firm-worker matches whose $x$ is too low to stay on the island. These are likely to be the matches formed at lower location-specific productivity levels when the island had a high $z$. Let $\Xi$ denote the total value of the current match. Using equations (17) and (20), the total value is given by

$$
\Xi(x, \mathbf{s})=y(x, z, \tilde{E})+\beta(1-\lambda) \mathbb{E}\left[\Xi\left(x, \mathbf{s}^{\prime}\right) \mid \mathbf{s}\right]+\beta \lambda \mathbb{E}\left[H\left(x^{\prime}, \mathbf{s}^{\prime}\right) \mid x, \mathbf{s}\right] .
$$

Since the value of a separated firm is zero, it is efficient to separate matches whenever the total match surplus $\Xi(x, \mathbf{s})-M$ becomes negative. However, given the calibration in Section 4 , $\Xi(x, \mathbf{s})>M$ for all realized values of $(x, \mathbf{s})$ and, thus, there is no endogenous separation. This is not to say that endogenous separation is irrelevant to local labor market dynamics. Instead, it means that there is no inefficient match in the model economy. The main reason behind this result is that the flow value of the dynamic equation (C.5), $y(x, z, \tilde{E})=x z \tilde{E}^{-\phi}$, remains well above the flow utility of a mover, $b-C$. Specifically, first, the stochastic process for $z$ is approximated by a finite-state Markov chain and the lowest value taken by $x z$ is

much larger than $b$. Second, the values taken by $\tilde{E}^{-\phi}$ are very close to 1 , as indicated by equations (C.3) and (C.4). Third, the moving cost, $C$, is approximately five times higher than the flow output of a firm, $y(x, z, \tilde{E})$.

\section{C.5 Random versus directed search across islands}

Kambourov and Manovskii (2009) argue that assuming random versus directed search across markets is less important when the model period is short like the one considered in this paper. Further, location-specific productivity shocks in the model make the difference between random and directed search even less important because workers in the model take into account not only the local labor market condition $\mathbf{s}=(z, \mu)$ but also their location-specific productivity $x$. In other words, workers may prefer to move to islands where they have high $x$, even though local labor market conditions on the new island are worse than those in the initial location. For this type of move, assuming random versus directed search across labor 
markets is inconsequential. Therefore, the main difference caused by random versus directed search across markets is the number of repeat moves. Since, in the calibration, individuals' lifetime utility varies more along location-specific productivity $x$ than labor market condition s, repeat mobility is negligibly small compared with unemployment. Moreover, unemployment duration is much longer than the model period. Therefore, the number of repeat moves in the model is too small to have any significant impact on the simulated moments.

Even if repeat mobility were large, there are various ways to embed the model with random mobility into a setting with directed mobility. One simple way is to count a repeat mover as a resident of his or her initial location until he or she settles in a particular labor market. Therefore, as long as repeat mobility is not directly targeted, assuming random versus directed search across islands is less important in the current model. For theoretical properties of models with random search, see Alvarez and Veracierto (2000).

\section{References}

Galindev, R., Lkhagvasuren, D., 2010. Discretization of highly persistent correlated AR(1) shocks. Journal of Economic Dynamics and Control 34, 1260-1276.

Krusell, P., Smith, Jr., A. A., 1998. Income and wealth heterogeneity in the macroeconomy. Journal of Political Economy 106, 867-896.

Rouwenhorst, G. K., 1995. Asset pricing implications of equilibrium business cycle models. In: Cooley, T. (Ed.), Structural Models of Wage and Employment Dynamics. Princeton University Press, Princeton, pp. 294-330

Shimer, R., 2001. The impact of young workers on the aggregate labor market. Quarterly Journal of Economics 116, 969-1007. 